\title{
BIOLOGIA DE ANOFELINOS AMAZÔNICOS. XII. OCORRÊNCIA DE ESPÉCIES DE ANOPHELES, DINÂMICA DA TRANSMISSÃo E CONTROLE DA MALÁRIA NA ZONA URBANA DE ARIQUEMES (RONDÔNIA) (1)
}

\begin{abstract}
RESUMO
Dados sobre o grau de incidência e distribuição de espécies Anopheles, em Ariquemes (RO), evidenciaram que a diversidade é maior na periferia da cidade e que Anopheles darlingi é registrada em praticamente todas as localidades de coleta. $O$ inquérito entomológico revelou niveis diferentes de penetração da espécie na área urbana, podendo-se constatar que os Setores 1 e 3 são áreas livres de malária; Setores 2 e 4 mostram riscos na periferia; e a Área Industrial e Setor de Áreas Especiais, Conjunto BNH, Setor 5 e Vila Velha constituem áreas de alto risco da malária. Nestes últimos, os índices de mosquitos por homem/hora foram os mais elevados, observando-se variaçōes no decorrer das amostragens e conforme a localização da área urbana. Medidas de densidade populacional revelaram mudanças estacionais, sendo os menores valores registrados no período de inverno. A transmissão da malária é discutida, considerando-se: 1) o papel da estrutura física da cidade, na época da fundação, 2) os igarapés que margeam a área urbana e suas relações com o ciclo de desenvolvimento dos anofelinos, 3 ) os padrões comportamentais da atividade de picar das espécies correlacionados a ambientes naturais e às áreas ecologicamente alteradas, e 4) a importância do manuseio ambiental no controle da malária, para redução da densidade populacional. Para conter o processo migratório do vetor é proposto um cinturão de proteção à cidade, constituído de mata não densa, incluindo também proteção biológica para incentivar a zoofilia dos anofelinos. Os resultados de infecção natural, obtidos em áreas de autoctonia da malária, permitem citar $\mathbf{A}$. darlingi como vetor, sendo discutida a possibilidade de que outras espécies estejam envolvidas na transmissão.
\end{abstract}

UNITERMOS: Anopheles; Malária; Densidade populacional; Mudanças estacionais; Atividade de picar; Vetor; Controle da malária.

\section{INTRODUÇÃO}

Atualmente a região Amazônica é objeto de extensas alterações ambientais, em decorrência dos grandes empreendimentos que estão sendo instalados. Essas atividades introduzem modificações no ecossistema, afetando o complexo integrado organismo/ambiente e, dentre

(1) Trabalho subvencionado pelo Programa Polonoroeste/CNPq.

(2) Instituto Nacional de Pesquisas da Amazônia, Manaus (AM), Brasil. Instituto de Biociências UNESP — Campus de São José do Rio Preto, São Paulo, Brasil.

(3) Instituto Nacional de Pesquisas da Amazônia, Manaus (AM), Brasil. 


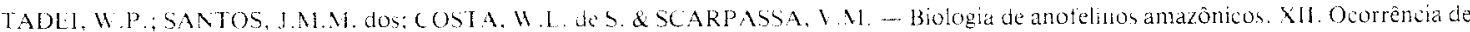

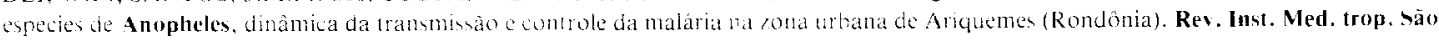
Paulo, 3013):221-251,1988

as doenças, a malária, como enfatizado na literatura\%. $\%$. 3 e a primeira a ocorrer em indices elevados nas áreas que vêm sofrendo alteraçós. Considerando-se os parâmetros que levam à manifestação da malária, como primcira endemia, ressalta-se: 1) a cxtensa ocorrência do(s) vetor(es) nessas regiòes de moditicaçoes o 2) o fato de que as populaçoes humanas imigrantes, freqüentemente, procedem de áreas livres da doenca e sào mais suscetiveis à infeccào por Plasmodium do que as populaçoes locais $\% .3 \%$. Exemplos classicos desse fato ocorreran durante o período de construçào da Estrada de ferro Madeira-Mamoré e na época da exploraçio da borracha na Amazonia.

A ocupacão da Amazônia Ocidental tem ammentado desde a construção das Rodovias BR-364 (Cuiabá/Porto Velho) e BR-319 (Manatus Porto Velho). Neste processo, a BR-364 constitui o elo de ligaçào entre esta regiào da Amazônia cos centros densamente povoados das regioes Sudeste e Sul do pais. Além desse aspecto, às margens desta rodovia são instalados grandes Pólos de Colonização, especialmente no Estado de Rondônia. Em consequência da alta migraçào humana para essas áreas, o assentamento das populaçóes migrantes o acompanhado da manifestação da malária cm intensidade máxima.

Dentre os Municípios do Estado de Rondonia, Ariquemes se destaca pela elevada migração humana, decorrente dos grandes Projelos de Assentamento que estão sendo instalados. Destaca-se também por ser o Município onde há a maior incidencia de malária do Estado. Os registros indican que os indices de ocorrência do Plasmodium falciparum é quase que o dobro em relação ao P. vivax. Em Ariquemes existem extensas áreas de terras férteis, porém, em contrapartida, como assinalou TADE[ 34 ", dados preliminares do inquérito entomológico para espécies de Anopheles estão demonstrando que A. darlingi, principal vetor da malária humana na Amazônia, é registrada em praticamente lodas as localidades estudadas. Esse aspecto, associado à migraçào elevada que está ocorrendo para a região, são elementos indicativos de que poderá haver un agravamento maior da incidência da malária no Município ${ }^{3 n}$.

Os potitos acima relatados evidenciam a importância de se realizar um inquérito entomológico para espécies de Anopheles, em áreas da Anazônia a serem ocupadas, para se estabelecer medidas de controle desta doença, com base no vetor. Considerando-se estes aspectos, neste trabalho são apresentados resulados do inquérito entonológico realizado na áréa urbana e perileria de Ariquemes, incluindo-se a diversidade especifica e a extensão de ocorrência dos anofelinos, nos diferentes Setores da cidade.

\section{ME NICIPIO DE: ARIQUEMES DESCRIÇÃO}

O Municipio de Ariquemes foi fundado em 1916, às margens do Rio Jamari, pelo Marechal Candido M.S. Rondon. O marco inicial da cidade loi a instalação de um dos postos telegrálïcon da linha Cuiabá - Santo Antônio do Rio Mideira. Além dos indios da tribo "Arikence", que eram os habitantes natos, os primeiros moradores da cidade foram os funcionarios do posto telegráfico e alguns seringueiros. O núcleo primitivo de Ariquemes ánda existe, marcado pelas atividades do posto lelegrático, porém o centro do povoado foi deslocado junto a pista de pouso da cidade, quando do apogeu do garimpo manual da cassiterita. Com a descoberta do minerio no Municipio, construiu-se o acroporto que centralizou as moradias e estabelecimento comerciais, pois os voos tornaram-se mais numerosos para o transporte do minério extraido e trazendo novos garimpeiros para a área.

$\mathrm{Na}$ evolução histórica da cidade é possível distinguir três ciclos economicos seqüenciais BORRACHA, CASSITERITA E AGRICULTURA. Com a queda do ciclo econômico da BORRACHA, que se constituiu no fator mais importante na primeira fase do Município, a extraçào do minério se tornou o fator preponderante na manutenção da cidade. A partir de 1971, quando o garimpo manual foi proibido, Ariquemes passou a ser mais um ponto de parada ao longo da BR-364. A passagem dessa rodovia pela sede da cidade foi um evento relevante para a sua manutenção, quando da decadência dos ciclos da BORRACHA e CASSITERITA.

Em 1971 comecaram os estudos realizados pelo Instituto Nacional de Colonização e Reforma Agrária (INCRA) ná área, dos quais resulıou a criaçào dos Projetos de Assentamento Dirigido "Burareiro" e "Marechal Dutra". Em 1975, estes projetos entraram em fase de 


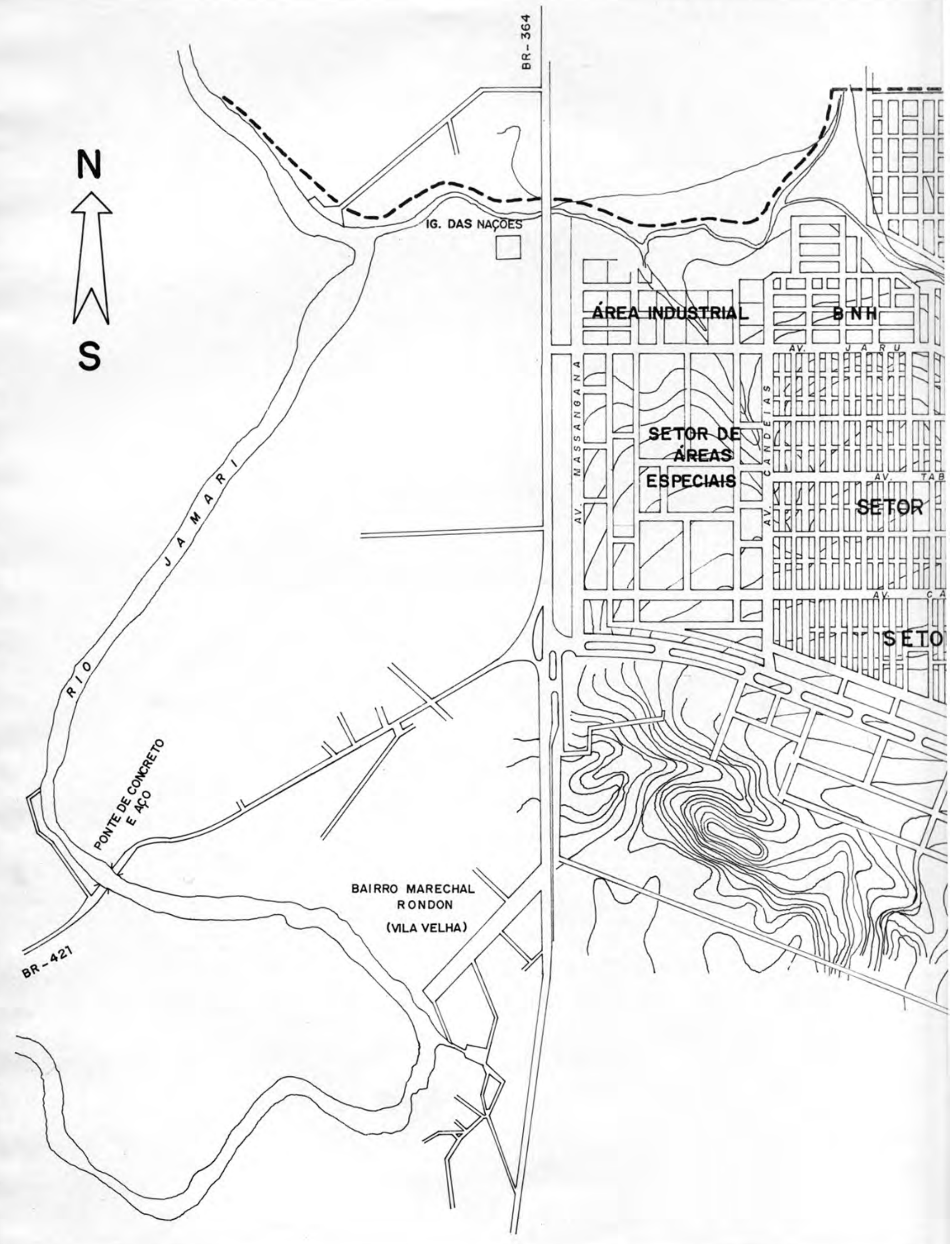




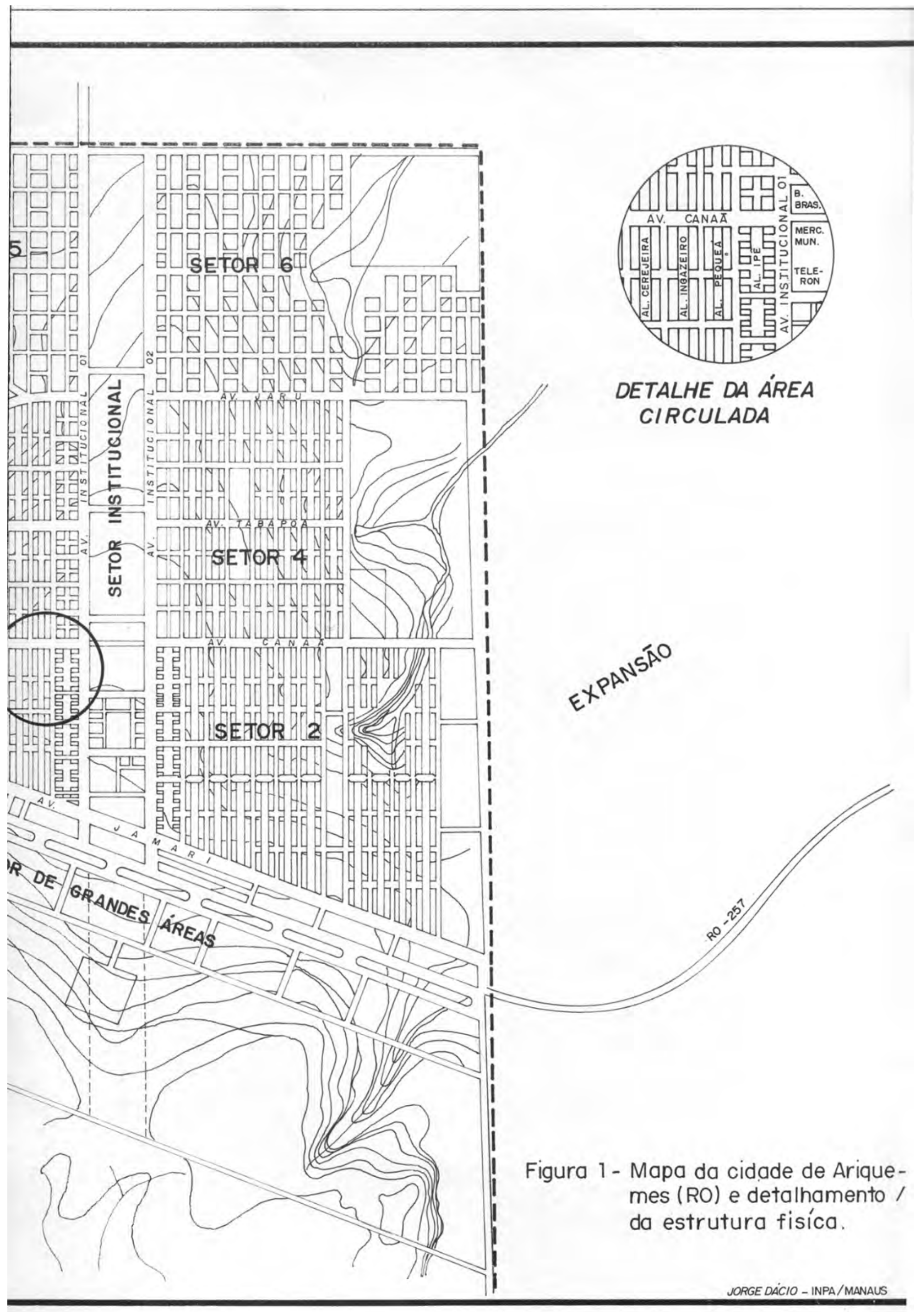




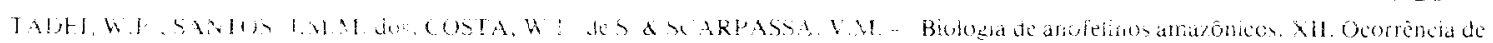

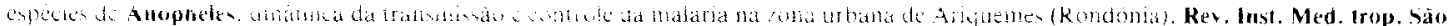

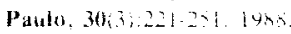

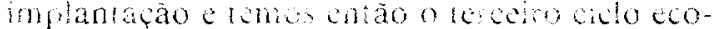
nónico de Ariquemes - AGRICUTTKA

No ano de 1970 a "Nova Ariquenes" toi lindada para receber o grarde huxo de migafao hunana cria decorrencía dos polos de colonizaţo. Iniciancinc, tentava-se a transterência da antiga Ariquentes para a nova cidade de Anquemes. Oprojeto inicial incluía a erradicaras do primeiro núcleo, victo ser ele cortado ao centro pela BR-364, yue the servia de eixo. Apesar das tentativas. a velha Sede de Ariquemes permaneceu e hoje está incluida como mais um bairro no plano urbano. A cidade foi inciada me Setor ! que lon, no mesmo ano de fundaao, totalmente tonado e chão inicions-se a urbanizacão do Selor 2. O Munictpio conta, atualmente. com cerca de 102.000 habitantes; a cidade está anipliando o perimeno urbano, e o Selor 6, o mais reconte, ja está prationente todo implantado (detalhes no mapa da cidade -... figura $1 \%$.

\section{MATERIAL METOHW}

Para compor o inquérito entomologico para espécies de Amopheles, realizado na área urbana e imediaçoes de Ariquemes, as coletas foram desenvolvidas tanto de insetos na forma alada, como na forma larvária. Os dados foram obtidos en duas etapas, de acordo com as atividades na área. A primeira, cujas atividades foram menores, foi realizada apenas em julho/agosto de 1981 e a segunda, a partir de agosto de 1984 e primeiro semestre de 1985.

Na obtenção das formas imaturas, foram realizadas coletas en criadouros localizados na periferia da cidade, os quais most ravam condiçós favoraveis para reprodução dos anofelinos. Nas figuras 2 a 4 são apresentados asnectos gerais desses criadouros, siluados no lgarapé das Naçoes (figura 2), no igarapé do Setor 2 (figura 3), e nas Chácaras localizadas no Setor de Grandes Areas e Área Nobre (figura 4). Como tïa evidenciado por essas figuras, foram amostrados criadouros que apresentavam características de áreas nào atteradas, como os situados no lgarapé das Naçoes e criadouros localizados em áreas modificadas pelo homem, como os existentes nas areas de pastagens nas Chácaras do Setor de Grande Areas Area Nobre, e no lgarapé do Setor 2.

Para as amostragens das formas imaturas. ws spéciates foran colctados con auxilio de una bandeja esmaltada de branco, retangular, medindo $32 \mathrm{~cm}$ de comprimento, $23 \mathrm{~cm}$ de largura e $6 \mathrm{~cm}$ de profundidade. Nas capluras, a bandejá era introduzida no local selecionado, de forma a provocar um fluxo de água no sentido do criadouro para a bandeja, arrastando para dentro da mesma as formas imaturas presentus no local. Em seguida, as larvas de 3. e 4". esladion eram coletadas coni um conta gotas e colocadas em trascos pora constitiirem a amostra. Essas capturas foram realizadas as margens dos criadouros, entre as plantas (gramineas, marótitas, algas, etc), folhas secas, galhos e troncos de arvores em decomposição e também entre pedras, quando existentes. Em situaçōes em que galhos e troncos ocupavam uma posifáto mais central nos criadouros também foram a calizadas captuas junto aos mesmos.

Para quanificiar as amostras, em cada local de coleta foi selecionada uma área de aproximadamonte très metros às margens dos criadouros, cas larvas foram obtidas imergindo-se a bandeja. em difurentes posiçòes nessa área, por liversar ves, are que não mais surgissem larvas nas mesmas, apos a emersăo. Em pontos de coletas nos quais não foi possivel selecionar uma área com as dimensòes citadas, a amostragem foi realizada em um espaço mais restrito, porém, o mesmo procedimento de imersões repetidas da bandeja, em cada local, foi empregado.

As larvas, após a coleta, foram fixadas em solução de MAC-GREGOR2x e transportadas para o laboratorio para posterior montagem e identificcação das espécies, sendo a clarificacão feita $\mathrm{em}$ solução de potassa e diafanização em creosoto. Para os casos em que nào é possível identificar as espécies pela forma imatura, a incidencia das mesmas foi determinada a partir de eclosoes de larvas procedentes diretamente dos criadouros.

Na coleta dos alados, foram efetuadas capturas junto à mata que circunda a cidade, nos diterentes Setores, e na área urbana, em diversos locais na periferia. Os espécimes foram capturados com auxilio de um aspirador, quando pousavam nas pessoas para se alimentar. O periodo de coleta foi fixado entre 18:00 e 22:00 horas para os diferentes pontos de amostragens. En cada coleta, foram anotados o número de iscas e o mumero de capturadores, objervando-se calcular o indice de anofelinos por homem/hora, para cada Setor da cidade. 
TADEI, W.P. SANTOS, J M MI dos; COSTA, W.L. deS. \& SCARPASSA, V.M. - Biologia de anofelinos amazônicos. XII. Ocorrência de especies de Anopheles, dinâmica da transmissão e controle da malái ia na zona urbana de Ariquemes (Rondónia). Rev. Inst. Med. trop. Sào Paulo, 3013):22\}-251, 1988

\section{A}

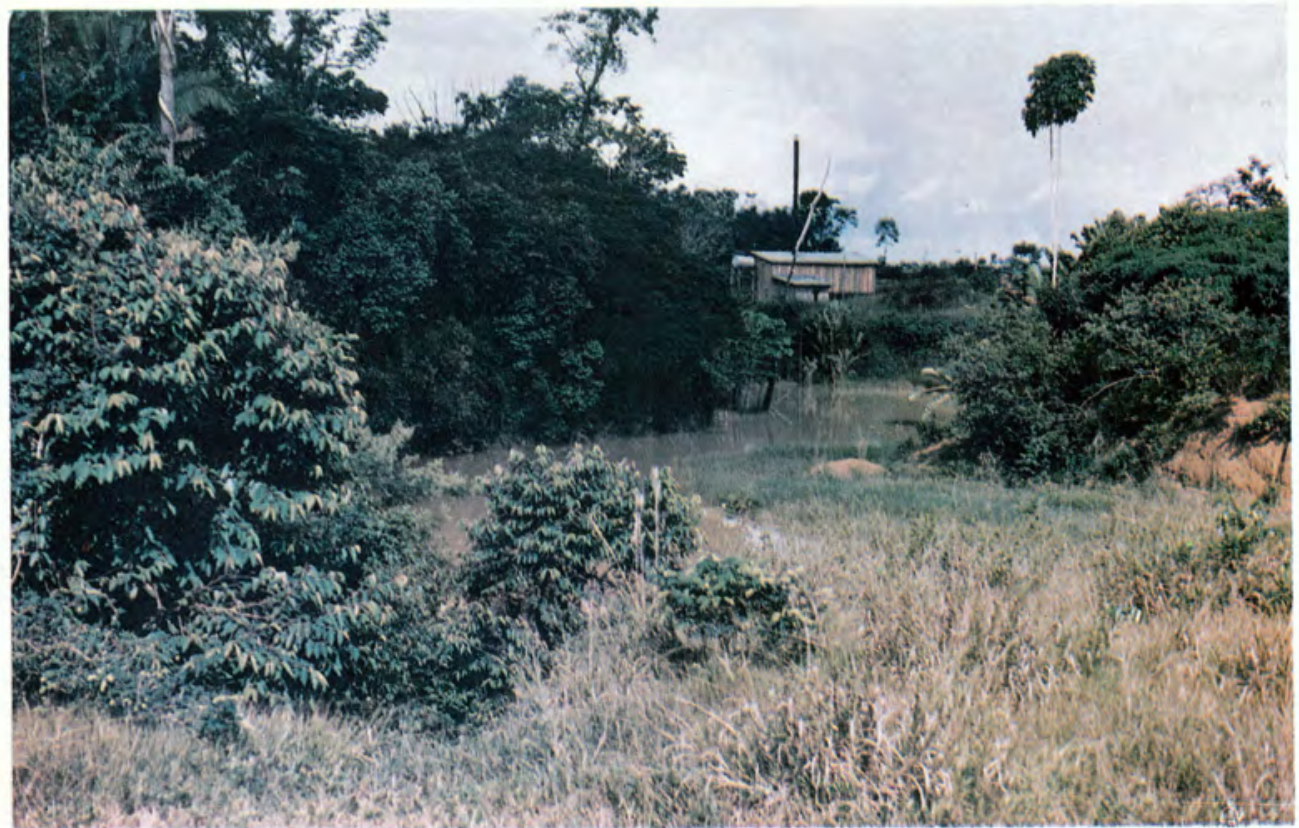

B

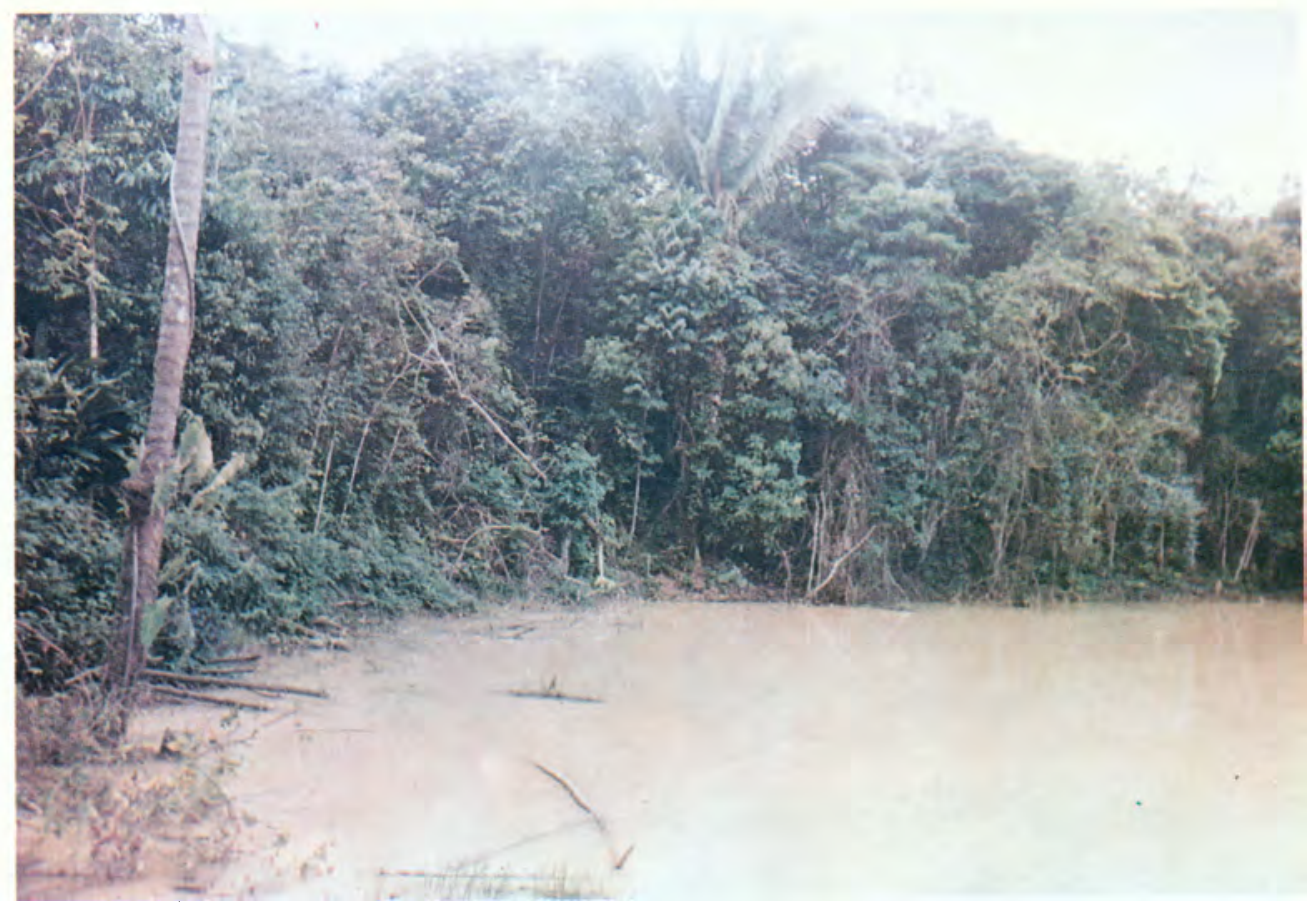

Fig. 2 - Aspectos dos criadouros no Igarapé das Naçoes. Em A, criadouro no início do período de inverno; em B, criadouro no periodo de inverno. 
TADEI, W.P.; SANTOS, J.M.M. dos; COSTA, W.L. de S. \& SCARPASSA, V.M. - Biologia de anofelinos anlarônicos. XII. Ocorrência de espécies de Anopheles, dinànica da transmissão e controle da maáăria na zona urbana de Ariquemes (Rondônia). Rer. Inst. Med. trop. São Paulo, 30(3):221-251, 1988.

A

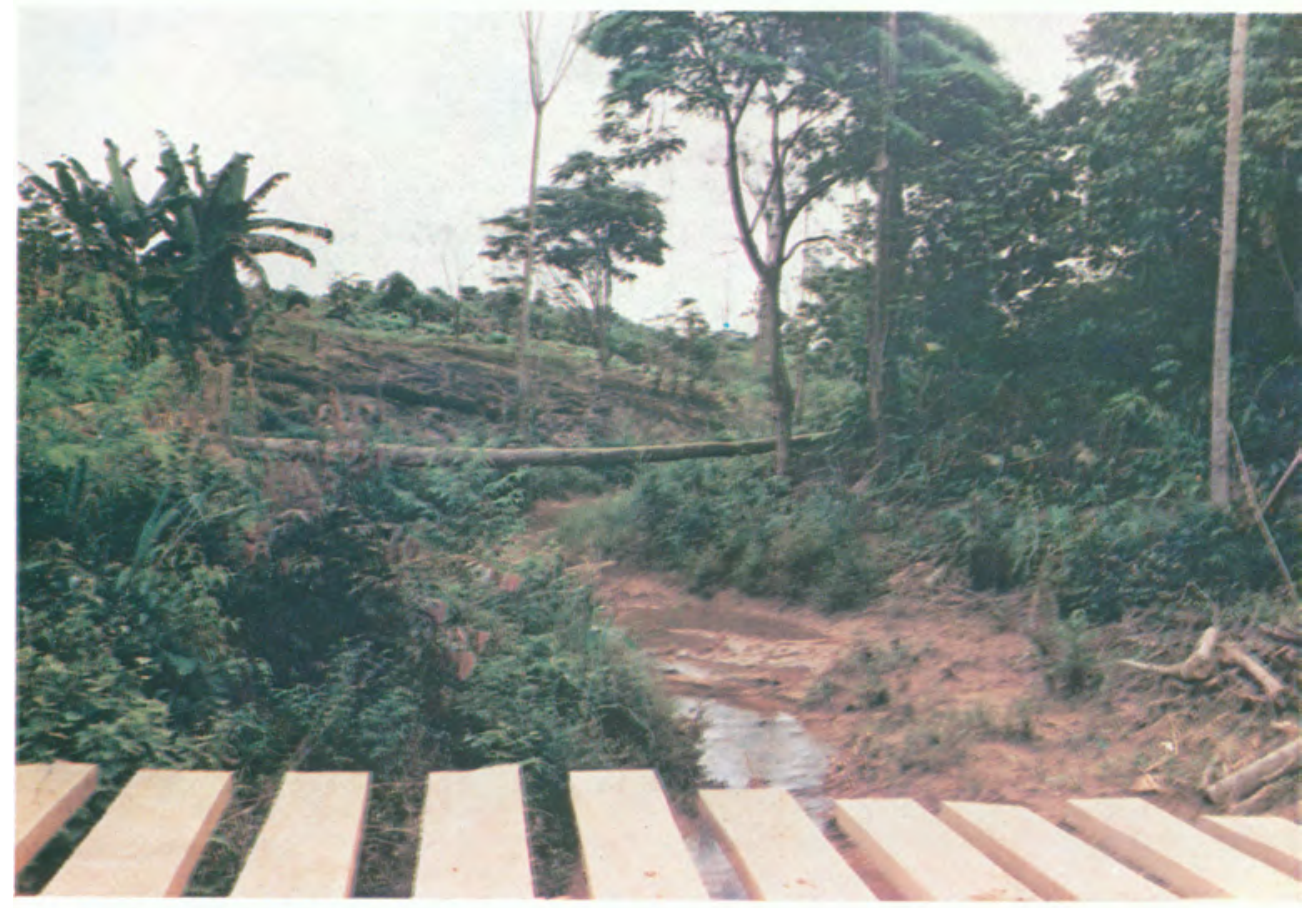

B

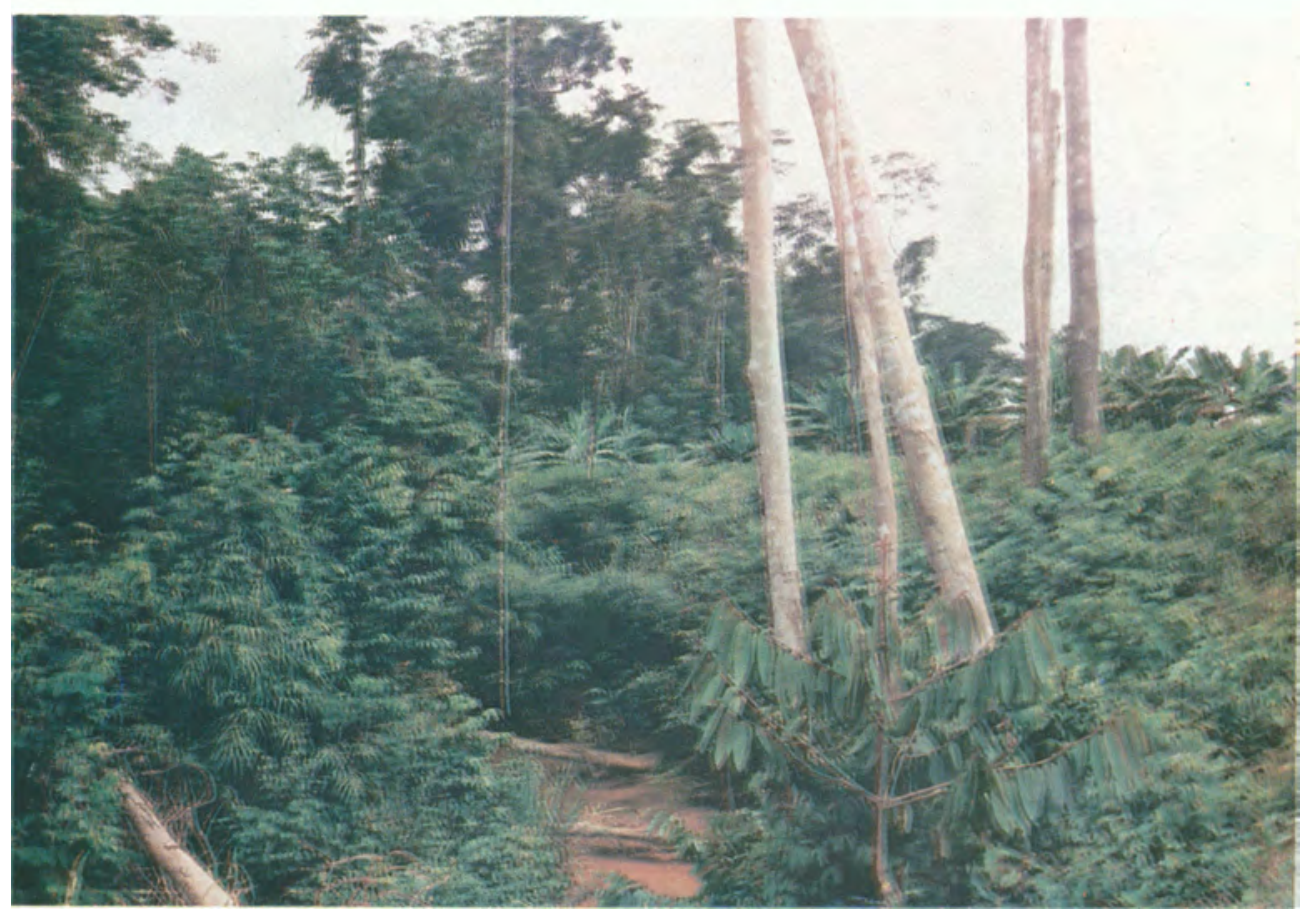

Fig. 3 - Igarapé do Setor 2. Em A, junto à cidade; em B, nas imediações das chácaras. 
TADEI, W.P. SANTOS, J.M.M. dos; COSTA, W.L. de S. \& SCARPASSA, V.M. - Biologia de anofelinos amazônicos. XII. Ocorrência de especies de Anopheles, dinâmica da transmissão e controle da malária na zona urbana de Ariquemes (Rondônia). Rev. Inst. Med. trop. São Paulo, 30(3):221-251, 1988.

A

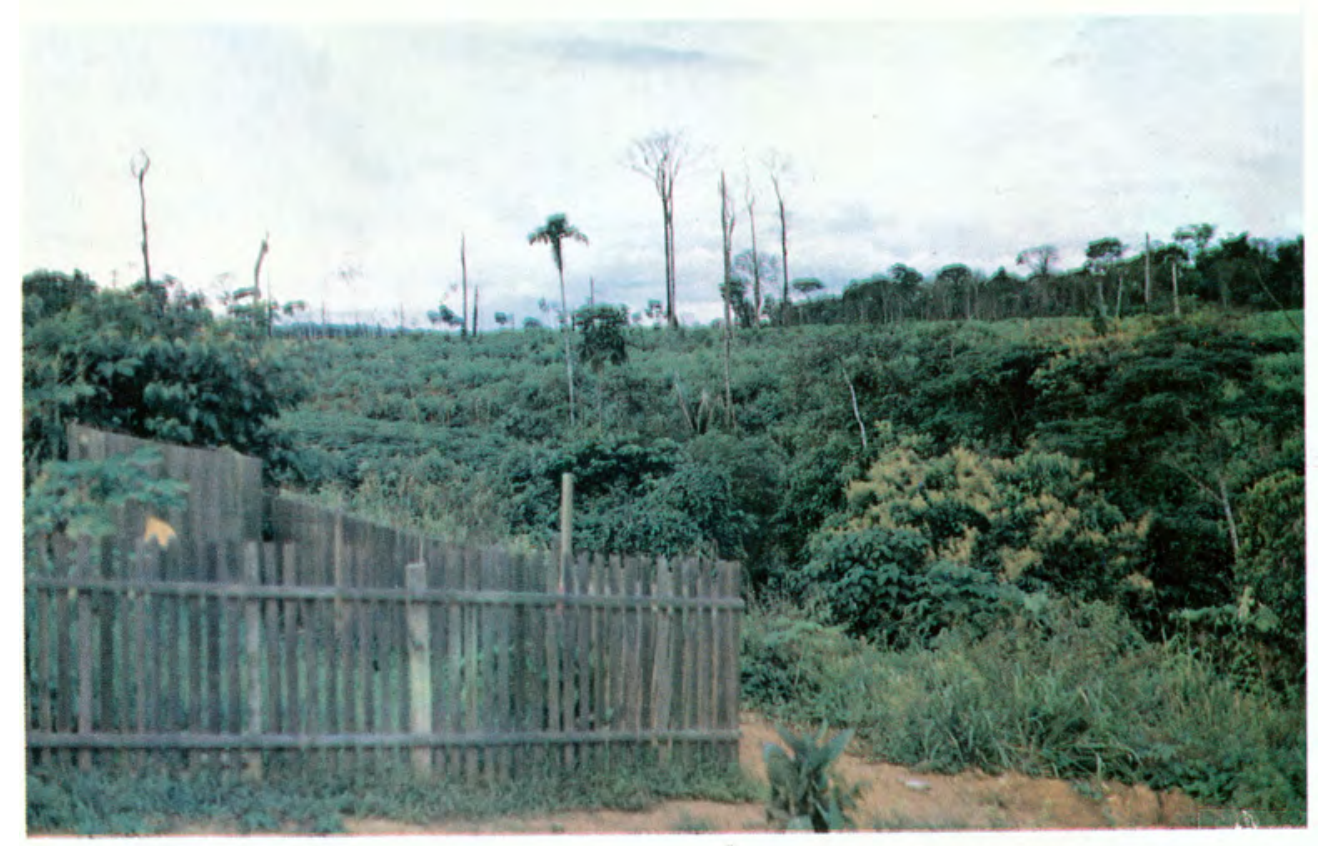

B

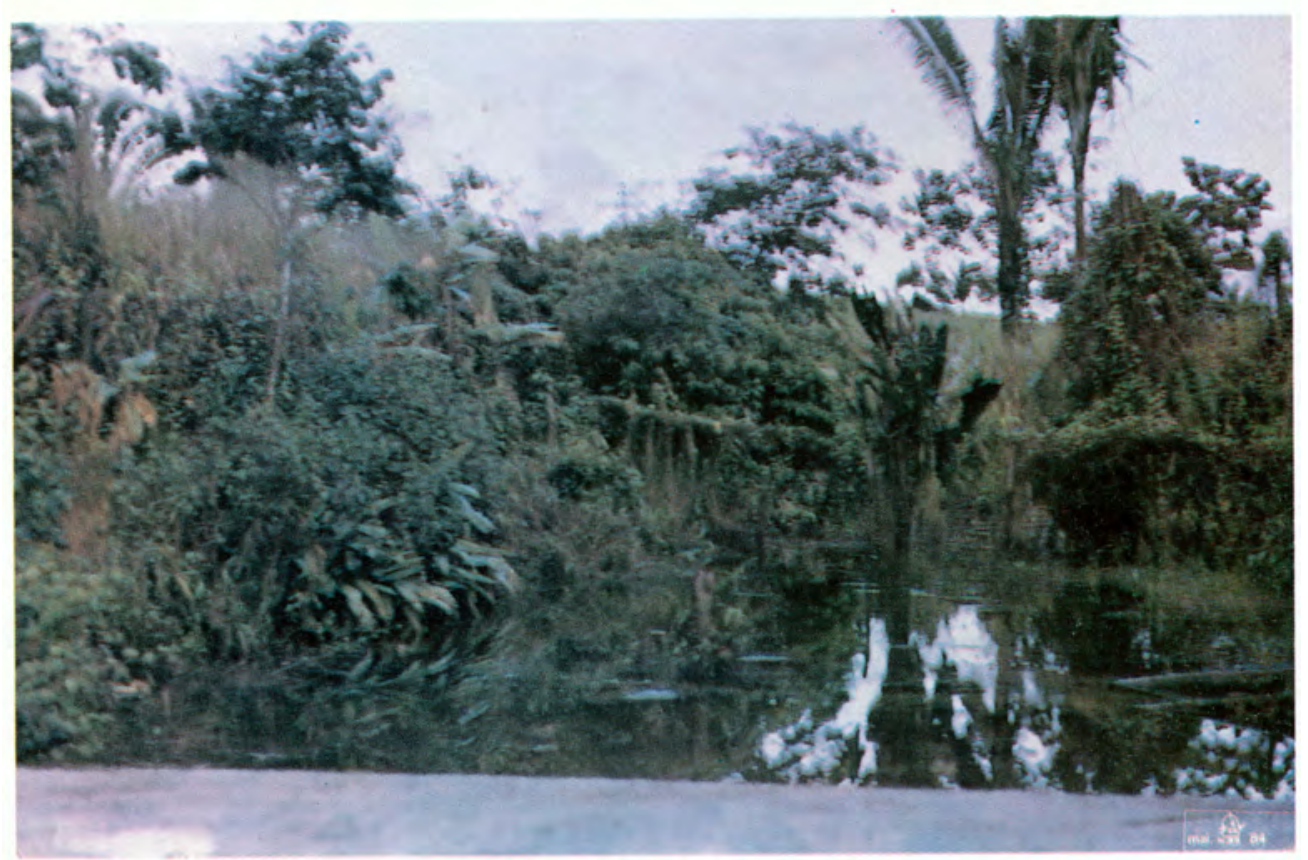

Fig. 4 - Aspecto geral (A) e detalhes de Criadouros (B) junto às chácaras no Setor de Grandes Áreas e Área Nobre. 


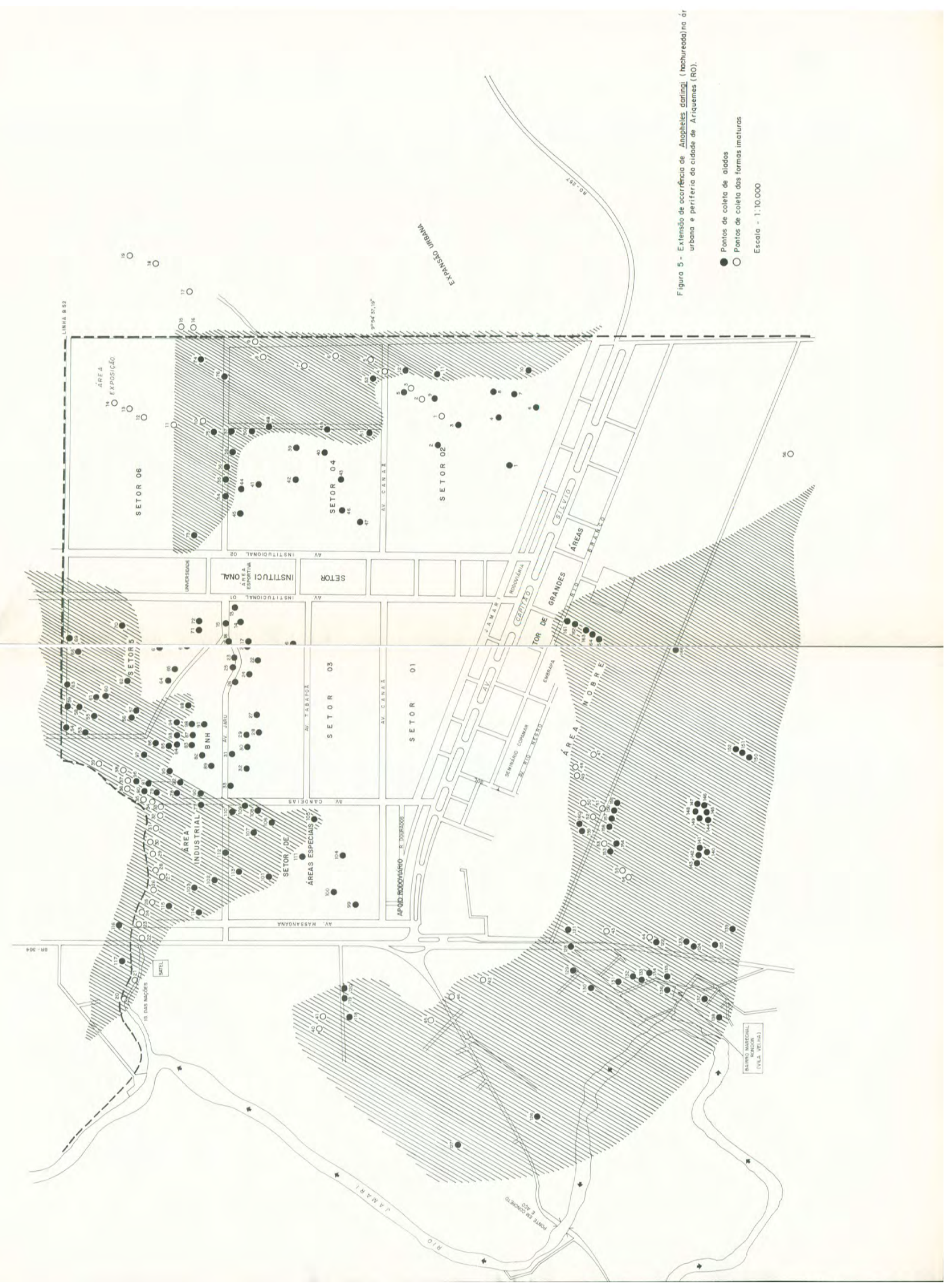




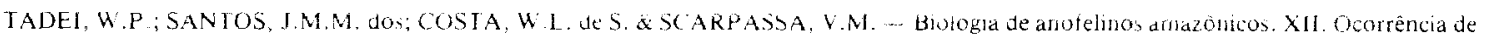
especies de Anopheles, dinärncea da transmissao e controle da malaria na cona urbana de Ariquemes (Rondonias Rev. Inst. Med. trop. Sáo Pauto, 3013).221-251. 1988

Concudo, pala medidas da atividade de pisat, foram feitas tambem capturas com 6 horas de observação (entre 18:00 e 24:00 horas) e com 12 horas (entre 18:00 horas e 6:00 horas da manhã seguinte).

Para a captura dos alados, junto ao Igarapé das Nações, foram feitas coletas às margens do mesmo e em meio à mata, na Área Industrial, e no Conjunto BNH. No Setor de Grandes Áreas e Área Nobre, como predominam Chácaras, as capturas foran desenvolvidas jun to ao Igarapé que percorre as mesmas, em áreas de pastagens e junto às residencias dessas Chácaras, em condiçoes peridomiciliares (figura 4). Na Vila Velha as capturas foram também peridomiciliares e alguns pontos ficaram situados junto à mata e mesmo mata adenro, face à proximidade da mesma em relacăo à ila.

$\mathrm{Na}$ área urbana, nos diferentes Setores, as capturas foram feitas sequencialmente da periferia para o centro da cidade. As coletas foram peridomiciliares e a medida em que os resultados eram positivos em locais periféricos, novos pontos de colela eram demarcados em áreas mais internas de cada Setor, no sentido de cobrir a área como um todo, cm direçào ao centro da cidade. A repeticão sucessiva desse procedimento possibilitou delimitar os pontos de amostragens que ficaram situados da periferia para o centro, sendo classilicados de positivose negativos, conforme o registro de anofelinos. Não houve necessidade de se estabelecer pontos de coleta no Setor 1 , pois as coletas já se mostraram negativas em áreas dos Setores 2 e 3 . Nas Alamedas, em vista das condiçòes propiciadas pela vegetação para a presença de alados, também foram realizadas capturas.

Para estudo da infecçào natural dos anofi. linos foi empregado o método usual de dissecções. Os espécimes capturados foram dissecados e examinados o estômago e as glândulas sa livares para a presença de oocistos e esporozoitos, respectivamente. As analises forain realizadas em microscopio de tase (Zeiss WL.).

Os espécimes colecionados, tanto na forma alada, cono na forma imatura, Coram trasisportados para o laboratóio montado iunto à Secretaria Municipa! de Saude, para o preparo e primeiras riagens no processo de idcntificacão. Posteriormente, todo o material foi encaminhado a Manaus para a determinação definiliva. Para identificação taxonômica das espécies da Série Oswaldoi e da Série Srrodei especialmentels, foram feitas montagens eni lâ- minas da genitalia dos machos. Os especimes colecionados fazem parte do acervo entomológico an Laboratório de Vetores da Malária do Instituio Nacional de Pesquisas da Amazônia e do Departamento de Biologia do Instituto de Biociências, Letras e Ciências Exatas UNESP, Campus de São José do Rio Preto, São Paulo.

\section{RESULTADOS}

Nas tabelas I e 2 conctam as descrições dos pontos de coleta de anofelinos com os resultados e respectivos números de referencia na figura 5. Para as coletas dos alados (Tábela 1), foram feitas capturas em 166 pontos da cidade e imediaços. como node ser verificado pela fi. gura, esses locas foram suficientes para cobrir toda a area urbana para o registro de ocorrência de alados. As coletas das formas imaturas (Tabcla 2) forain realizadas nos Igarapés que margeam a cidade, sendo feitas 56 capturas. O número de coletas foi maior no lgarape das $\mathrm{Na}$ çós devido a estreita relacão que o mesmo apresenta com a zona urbana e pelo fato de mostrar excelentes condiçōes de reprodução para anotelinos.

Considerando todo o material colecionado, nos dois periodos de atividade na zona urbana, registrou-se a ocorrência de 15 especies de Anopheles pertencentes aos subgênercs Nyssorhynchus. Arribalzagia e Anopheles. Subgênero Nyssorhynchus Blanchard, 1902

Anopheles darlingi Root, 1926

Anopheles triannulatus (Neiva \& Pinto, 1922)

Anopheles galvaoi Causey, Deane \& Deane. 1943

Anopheles rangeli rabaldón, CovaGarcia \& Lopez, 1940

Anopheles argyritarsis Robineau Desvoidy, 182 ?

Anophelos evarsae (Brithes, 1926)

Anopheles hemarrochi Chbaldón, Cova-Garcia \& Lopez, 1941

Anophzles nunez-rovari Gabaldón, 1940

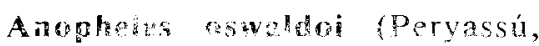
1922)

Anophelas abbitarsis Lynch Arribálzaga, 1879

Arophelos brandensis (Chagas, 1907) 


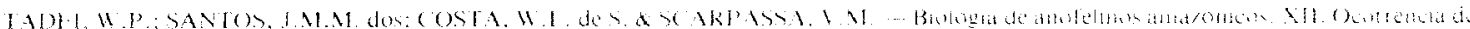

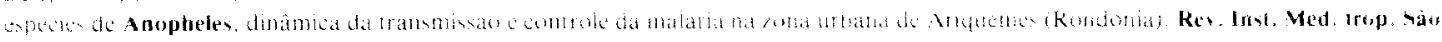
Patulo, 3013):22!-251, 1488.

TABL LA 1

Descrição dos pontos e resultados das coletas de anofeliros, na torma dada, nos diferentes sotures da cidade de Ariquemes (RO).

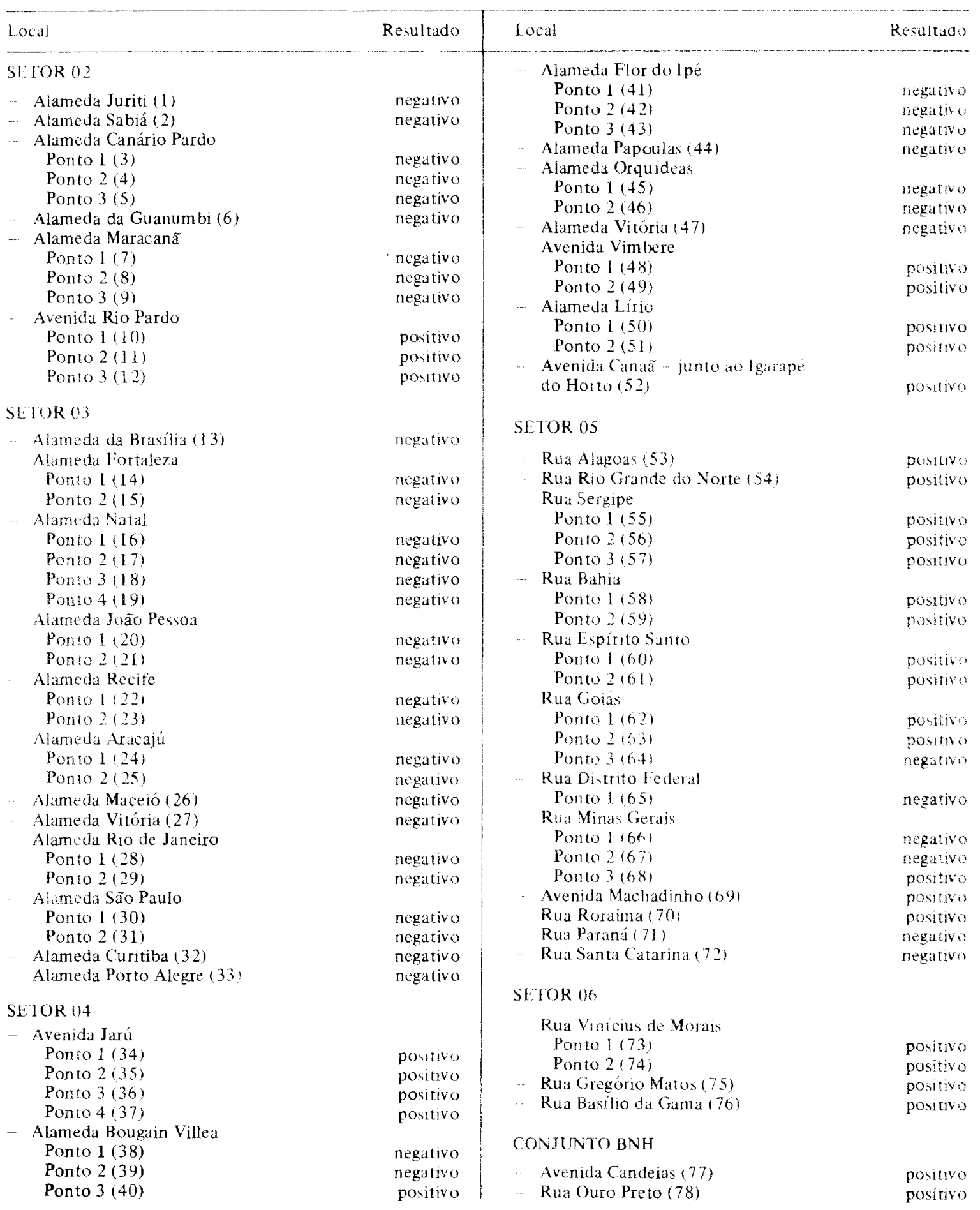


TADEI, W.P.; SANTOS, J.M.M. dos; COSTA, W.L. de S. \& SCARPASSA, V.M. - Biologia de anofelinos amazónicos. XII. Ocorrência de espécies de Anopheles, dinâmica da transmissão e controle da malaria na zona urbana de Ariquemes (Rondônia). Rev. Inst. Med. Irop. São Paulo, 30(3):221-251, 1988.

continuação. .

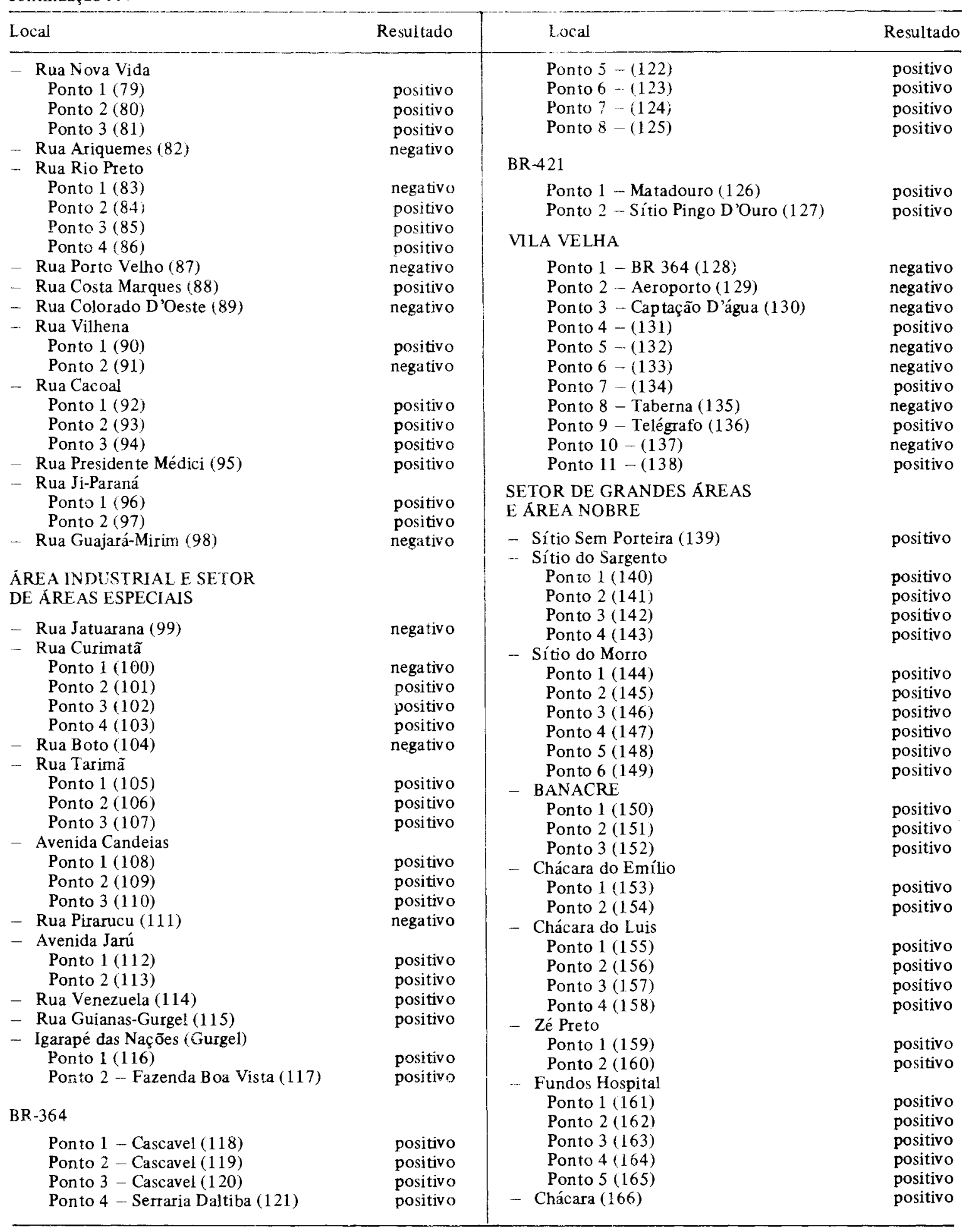

( ) Número de referência da figura 05 (CIRCULO CHEIO). 
TADEI, W.P.; SANTOS, J.M.M. dos; COSTA, W.L. de S. \& SCARPASSA, V.M. - Biologia de anofelinos amazônicos. XII. Ocorrência de espécies de Anopheles, dinâmica da transmissão e controle da malàia na zona urbana de Ariquemes (Rondônia). Rev. Inst. Med. trop. São Paulo, 30(3):221-251, 1988

TABELA 2

Descrição dos pontos e resultado das coletas de anofelinos, na forma larvária, nos Igarapés que margeam a cidade de Ariquernes (RO).

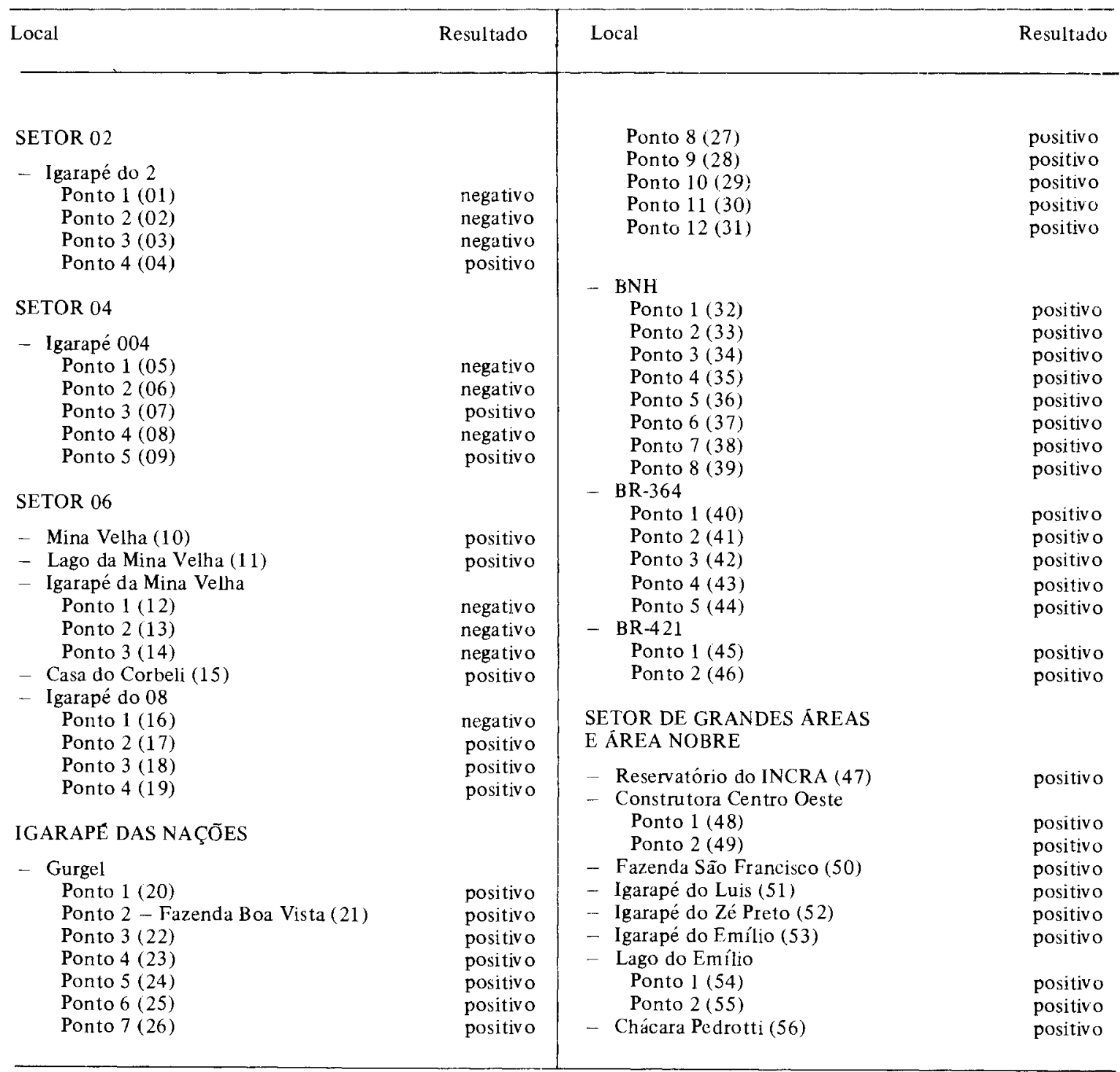

$(\quad)=$ Número de Referência da Figura 05 (CÍRCULO VAZIO). 


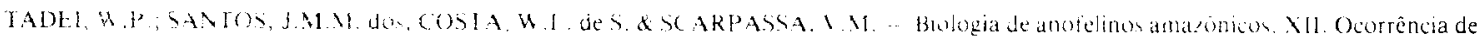

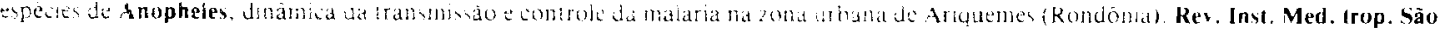

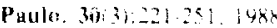

Anopheles surodei Root, 1926

Subgensto Arribalzagia Theobald, 1903

Anopheles mediopunctatus (Theobald, 1903)

Subgènero Anopheles Meigen, 1818

Anopheles peryassui Dyar \& Knab. 1908.

Anopheles mattogrossensis Lutz \& Neiva. 1911

As tabelas 3 a 5 referem-se a coletas realizadas na primeira etapa, cujos dados foram obtidos em julho/agosio de 1981. As capturas com 6 horas de observação (Tabela 3) foram reaizadas nas areas centrais dos Setores 2 e 3 e da Vha Velha. Foram feitas coletas em tres pontos do Setor 2, em quatro do Setor 3 e en dois na Vila Velha. Foram capturadas nove especies sendo que A. darlingi representou $76^{\circ}$ do soral colecionado: as outras especies mais frequentes foran A. rannulatus a A. oswal-

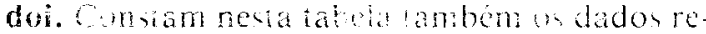
a aivos a atridade ue plear, mos diferentes hora-

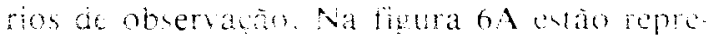
sentada as esneche que owreram na hoquen-

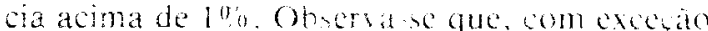
da A. mediopunctatus. as demais especies nostraram atividade elevada no primeiro horario: apos este, a alividade sofre reducoes em excá de $50^{\circ} 0$ e, para todas as enpécies, a atividad nào foi mais observada a nartir das 21:00 ... 22:00 horas. As demais especies constantes da tabela 3 mostraram atividade apenas no primci- ro horário, sendo capturados apenas alguns exemplares.

$\mathrm{Na}$ Tabela 4 estảo incluidas as coletas em pontos periféricos de Ariquemes, sendo obtidos dados em 3 pontos do Gurgel (Igarapé das Naçōes), em um na Fazenda Boa Vista (próxima ao Igarapé das Nações, na BR-364), e no reservatório do INCRA, situado no Setor de Grandes Áreas. Foram detectadas cinco espécies de Anopheles e novamente A. darlingi foi a mais freqüente, representando $91,1 \%$ do total colecionado; as outras duas mais frequientes, da mesma forma que o observado na tabela 3 , foram A. oswaldoi, e A. triannulatus. Os resultados relativos a atividade de picar, que neste caso compreende 12:00 horas de otservação, estào apresentados graficamente na figura $6 \mathrm{~B}$. $V$ erifica-se que $\mathbf{A}$. darlingi exibe um padrão de atividade que se destaca dos demais, pois o nesmo e contínuo, mas com dois picos, sendo um no inicio da noite e o segundo ao amanhecer, menos acentuado. As demais espécies $(\mathbf{A}$. triannulatus $\mathrm{C}$ A. oswaldoi) mostraram atividade apenas no incio da noite, que se encerra em tomo de 20:00 horas, e apresentam um novo pico ao ananhecer, entre 4:00 e 6:00 horas.

As colctas das formas inaturas, realizadas no periodo julho/agosto de 1981 , constam na tabcla 5 e os dados estão separados por localidade de coleta. Observa-se que existem diferencas na diversidade de espécies por localidade, expecialmente no registro de $\mathbf{A}$. darlingi que

IABLLA 3

Incidência de espécies de Anopheles, na forma alada. coletadas entre $18: 00 \quad 24: 00$ horas nos setores 2 e 3 e Vila Velha, no período julho/agosto de 1981 (Ariquemes - Rondônia)

\begin{tabular}{|c|c|c|c|c|c|c|c|}
\hline \multirow{2}{*}{ Espécie } & \multicolumn{6}{|c|}{ HORARIO } & \multirow{2}{*}{ Total } \\
\hline & $18 \cdot 19$ & $19 \ldots 20$ & $20 \cdots 21$ & $21 \quad \cdots 22$ & $22-23$ & $23 \ldots 24$ & \\
\hline Anopheles darlingi & $226(50,1)$ & $147(32,6)$ & $73(16.2)$ & $05(1.1)$ & 0 & 0 & $451(76,0)$ \\
\hline Anopheles trian nulatus & $65(80,3)$ & $12(14.8)$ & $04(4,9)$ & 0 & 0 & 0 & $81(13,7)$ \\
\hline Anopheles oswaldoi & $12(44,5)$ & $07(25.9)$ & $07(25,9)$ & $01(3.7)$ & 0 & 0 & $27(4,6)$ \\
\hline Anopheles mediopunctatus & 0 & $03(50,0)$ & $02(33.3)$ & $01(16,7)$ & 0 & 0 & $06(1,0)$ \\
\hline Anopheles nuñez-tovari & $05(100)$ & 0 & 0 & 0 & 0 & 0 & $05(0.8)$ \\
\hline Anopheles galvaoi & $03(100)$ & 0 & 0 & 0 & 0 & 0 & $03(0,5)$ \\
\hline Anopheles evansae & $12(66.7)$ & $0.5(27.8)$ & $01(5.5)$ & 0 & 0 & 0 & $18(3,0)$ \\
\hline Anopheles albitarsis & 020100 & 0 & 0 & 0 & 0 & 0 & $02(0,3)$ \\
\hline Anophetes argy ritarsis & $01(100)$ & 0 & 0 & 0 & 0 & 0 & $01(0,1)$ \\
\hline TOTAL & $326(54.9)$ & $174(29.3)$ & $87(14.6)$ & $7(1,2)$ & & & 594 \\
\hline
\end{tabular}

$1=$ percentagem 
TADEI, W.P.; SANTOS, J.M.M. dos; COSTA, W.L. de S. \& SCARPASSA, V.M. - Biologia de anofelinos amazônicos. Xil. Ocorrència de espécies de Anopheles, dinâmica da transmissão ectonırole da malária na zona urbana de Ariquemes (Rondônia). Rev. Insi. Med. trop. Sáo Paulo, 30(3):221-251, 1988.
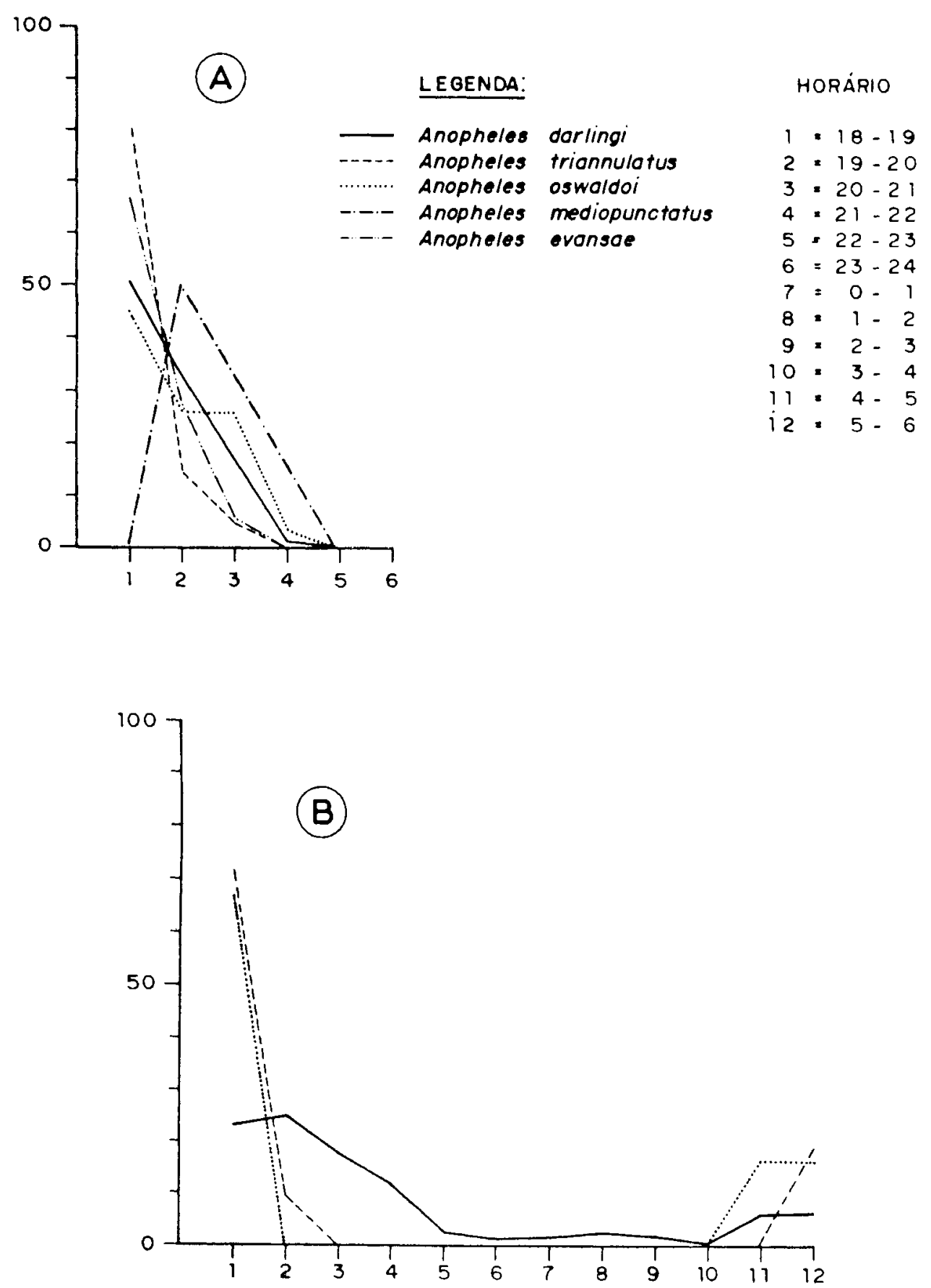

Fig. 6 - Representação gráfica das frequências de espécies de Anopheles observadas nos diferentes horários. Em A, observaçōes em 6 horas. Em B, observaçōes en 12 horas. Ordenada: percentagem do total. Abscissa: horários. 
TADEl, W.P.; SANTOS, I.M.M. dos; COSTA, W.I. de S. \& SCARPASSA, V.M. - Biologia de anofelinos amazônicos. XII. Ocorrência de especies de Anopheles, dirtámica da transmissão e controle da malária na zona urbana de Ariquemes (Rondônia). Rev. Inst. Med. trop. São Paulo, 30(3):221-251, 1988 .

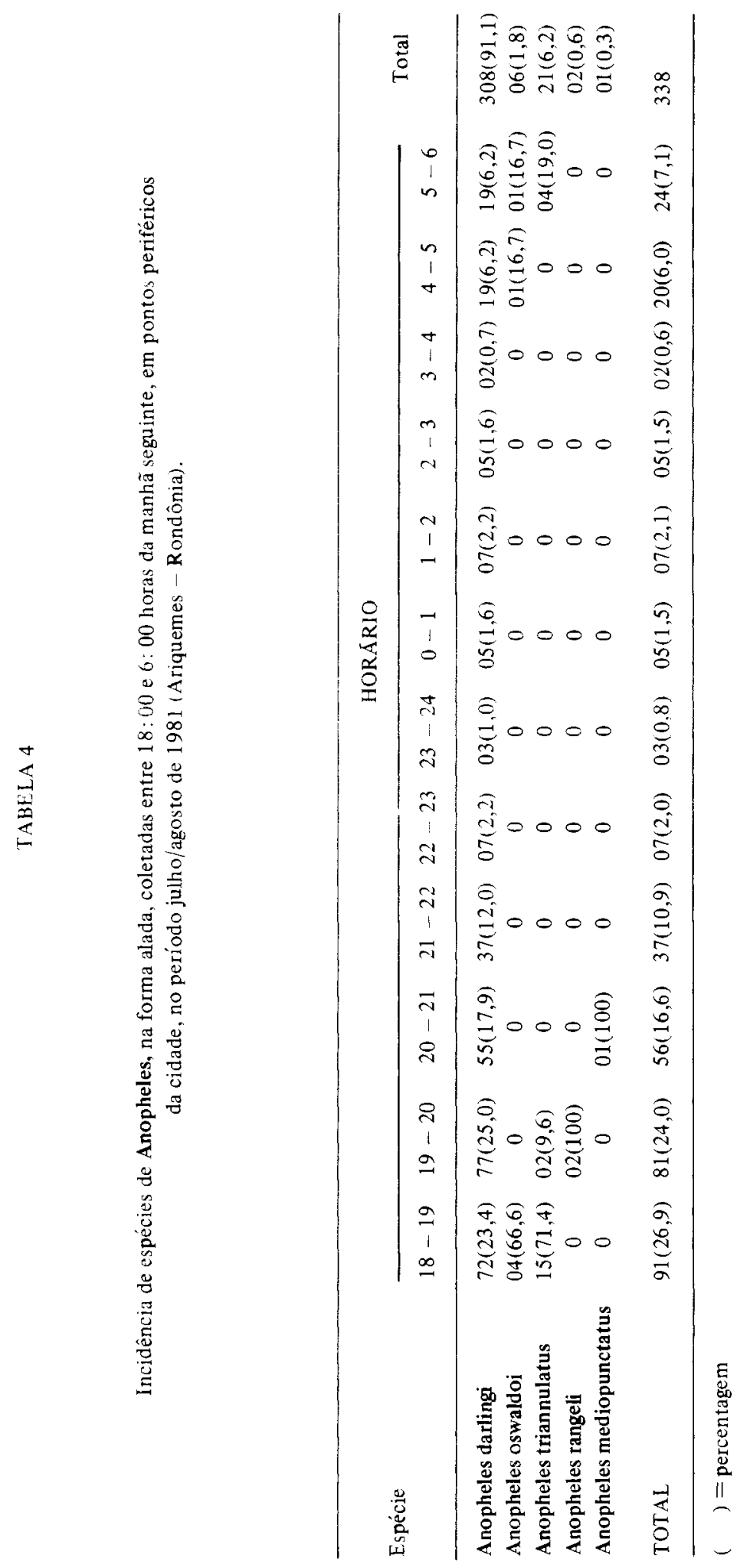


TADEI, W.P.; SANTOS, J.M.M. dos; COSTA, W.L. de S. \& SCARPASSA, V.M. - Biologia de anofelinos anrazônicos. XII. Ocorrência de espécies de Anopheles, dinâmica da transmissão e controle da nalária na rou urbana de Ariquemes (Rondónia). Rev. Inst. Med. trop. São Paulo, 30(3):221-251, 1988

mostrou incidência elevada no Gurgel, localidade do Igarapé das Nações. Destaca-se ainda na tabela 5, a extensão de ocorrência de algumas espécies que foram capturadas em grande número de localidades - A. triannulatus, A. rangeli, A. nuñez-tovari e A. oswaldoi. Do total de espécimes colecionados naquela época (4904 exemplares), verifica-se que no Gurgel (Igarapé das Nações) capturou-se $83 \%$ do material.

Os dados das tabelas 6 a 12 foram obtidos no segundo período de atividade, compreendido entre agosto de 1984 a junho de 1985. As colctas das formas aladas, constantes na figura 5 , nos diferentes Setores da cidade, estão incluidas na tabela 6 . Verifica-se que $\mathbf{A}$. darlingi é registrada em todas localidades e considerando-se o total de alados coletados a espécie representou $82,8 \%$. A outra espécie mais freqüente foi $\mathbf{A}$. triannulatus $(11,4 \%)$ e com valores rclativamente alio também A. evansae $(3,3 \%)$. As demais espécies mostraram valores abaixo de $1 \%$. Além de A. darlingi, que foi registrada em 10dos os Setores, A. Iriannulatus também mos1rou esta caracteristica. Da mesma forma que o observado durante as atividades do período julho/agosto de 1981, no qual constatou-se incidência clevada de anotelinos no Gurgel (lgarapé das Naçōes), situado na Área lndustrial c Setor de Áreas Especiais, nas atividades do segundo periodo este fato foi novamente constalado (Tabela 6), pois $65,7 \%$ dos anofelinos coletados foram capturados neste local. Dada esta característica, o Gurgel foi estabelecido como una Estação de Coleta e capturas foram realizadas durante 1984 e 1985 . Os resultados cstão representados na tabela 7 e observa-se que $\mathbf{A}$. darlingi foi registrada durante todo o periodo e apresenta variação na incidencia, conforme a época considerada. As demais espécies ocorreram em freqüências baixas e não nostraran um quadro contínuo de registro nas coletas. Anopheles triannulatus, contudo, foi registrada con baixa incidência em três amostragens. Levando-se em conta o total de anofelinos colecionados, constata-se que existem variaçoes na densidade e que as frequências sofren reduçóes de agosto de 1984 a janeiro de 1985 e os valores voltam a se elevar a partir de fevereiro de 1985.

Os resultados obtidos nas colctas das laras, realizadas nos diferentes Selores da cidade, estào incluidos na tabela 8 . Observa-se uma diversidade elevada, pois nove especies de Anopheles foram registradas e a incidencia maior de larvas foi constatada lambém no lgarapé das
Nações $(71,2 \%$ do total coletado), igualmente ao ocorrido em 1981. Novamente registrou-se que $\mathbf{A}$. darlingi foi a espécie mais frequente no Igarapé, representando $63 \%$ do total colecionado, e se repete o resultado também para $\mathbf{A}$. triannulatus e A. oswaldoi. Nos Setores 2 e 4 constatou-se larvas de anofelinos, porém o material não foi identificado por se tratar de exemplares no segundo e terceiro estádios. No Setor 6 a incidência foi muito baixa.

Comparando-se a incidência das espécies constante na tabela $8 \mathrm{com}$ a observada em 1981 (Tabela 5), verifica-se que $\mathbf{A}$. darlingi, $\mathbf{A}$. triannulatus e A. oswaldoi, espécies mais freqüentes na primeira amostragem, são também as que predominam em 1984/1985 (Tabela 8). Quanto à diversidade, em relação à segunda amostragem, registrou-se duas espécies a mais na primeira amostragem.

Dada a incidência elevada de anofelinos nas formas imaturas no lgarapé das Nações foram realizadas coletas para avaliação de densidade populacional em pontos determinados, em diferentes periodos (Tabela 9). Os resultados revelaram que $\mathbf{A}$. darlingi e $\mathbf{A}$. triannulatus foran espécies registradas em todas amostragens, sendo que a primeira representou $61,1 \%$ de todo o material colecionado e a segunda $20,4 \%$. A terceira espécie mais freqüente foi $\mathbf{A}$. oswaldoi, repetindo-se os resultados obtidos em 1981 (Tabela 5). Observa-se também que ocorre variaçào na densidade populacional, sendo os valores, no cômputo total, relativamente constantes de agosto a novembro de 1984 , havendo decréscino a partir de dezembro até abril de 1985, e aumento em maio e junho. A nivel especifico, constata-se que $\mathbf{A}$. darlingi apresenta frequiências elevadas até dezembro de 1985 , ocorrendo reduçôes a partir de fevereiro de 1985. Para A. triannulatus e A. oswaldoi no entanto, reduçōes na densidade já são registradas desde novembro de 1984.

Conforme mencionamos, os pontos de coleta da figura 5 estão descritos nas tabelas 1 e 2 e para delimitar a extensào de ocorrência dos anofelinos, na área urbana, utilizou-se o procedimento de registro de pontos positivos e negalivos, da periferia para o centro da cidade, relatado na metodologia. Este procedimento para o inquérito entomológico possibilitou avaliar o grau de incidência e distribuição das espécies de Anopheles, nos Setores da cidade.

Considerando-se o registro de pontos positivos e negativos para a presença de $\mathbf{A}$. darlingi, 
TADEI, W.P.; SANTOS, J.M.M. dos; COSTA, W.L. de S. \& SCARPASSA, V.M. - Biologia de anofelinos amazônicos. XII. Ocorrência de especies de Anopheles, dinâmica da transmissão e controle da malária na zona urbana de Ariquemes (Rondônia). Rev. Inst. Med. trop. São Paulo, 30(3):221-251, 1988 .

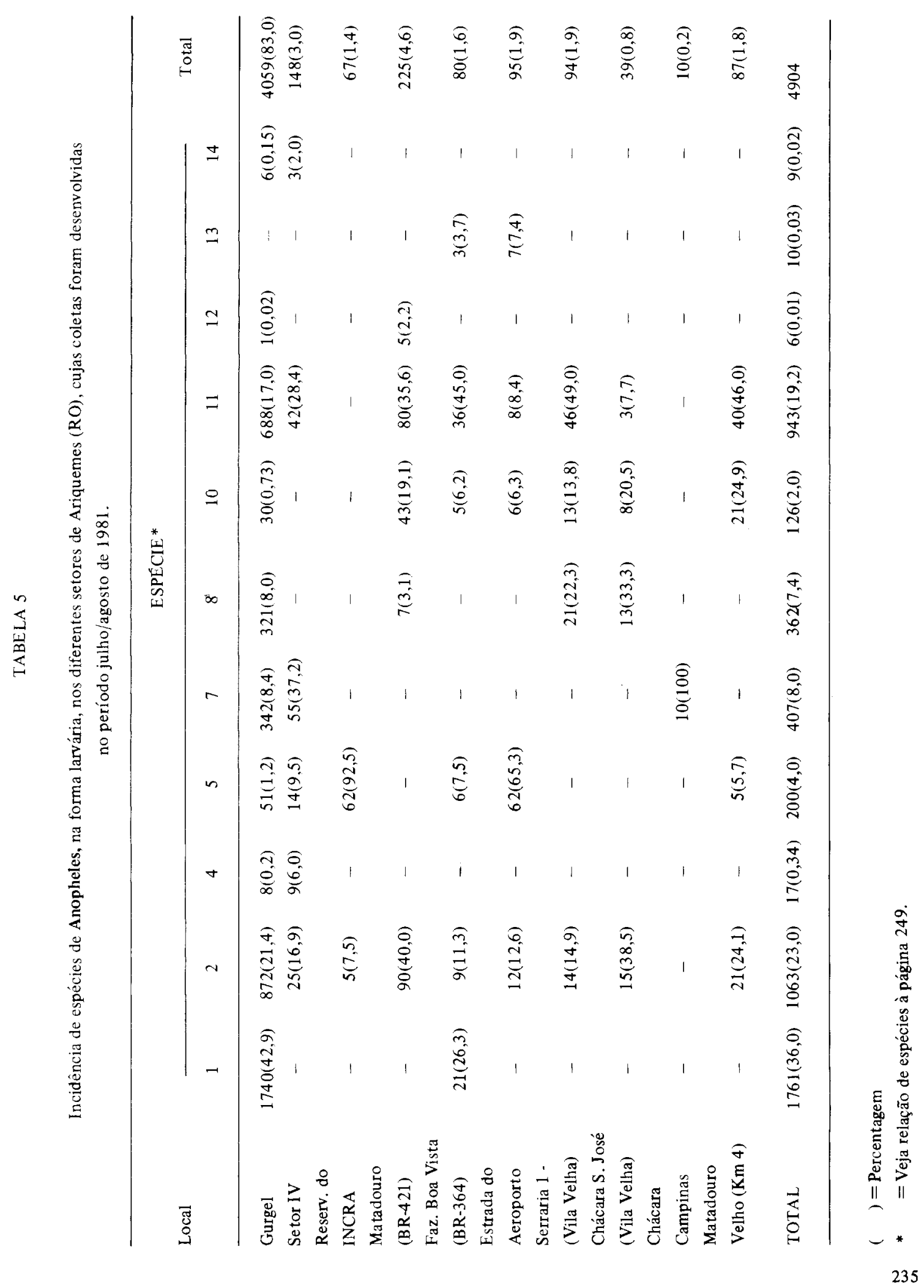


TADEI, W.P.; SANTOS, J.M.M. dos; COSTA, W.L. de S. \& SCARPASSA, V.M. - Biologia de anofelinos amazônicos. XII. Ocorrência de espécies de Anopheles, dinâmica da transmissão e controle da malária na zona urbana de Ariquemes (Rondônia). Rev. Inst. Med. trop. São Paulo, 30(3):221-251, 1988.

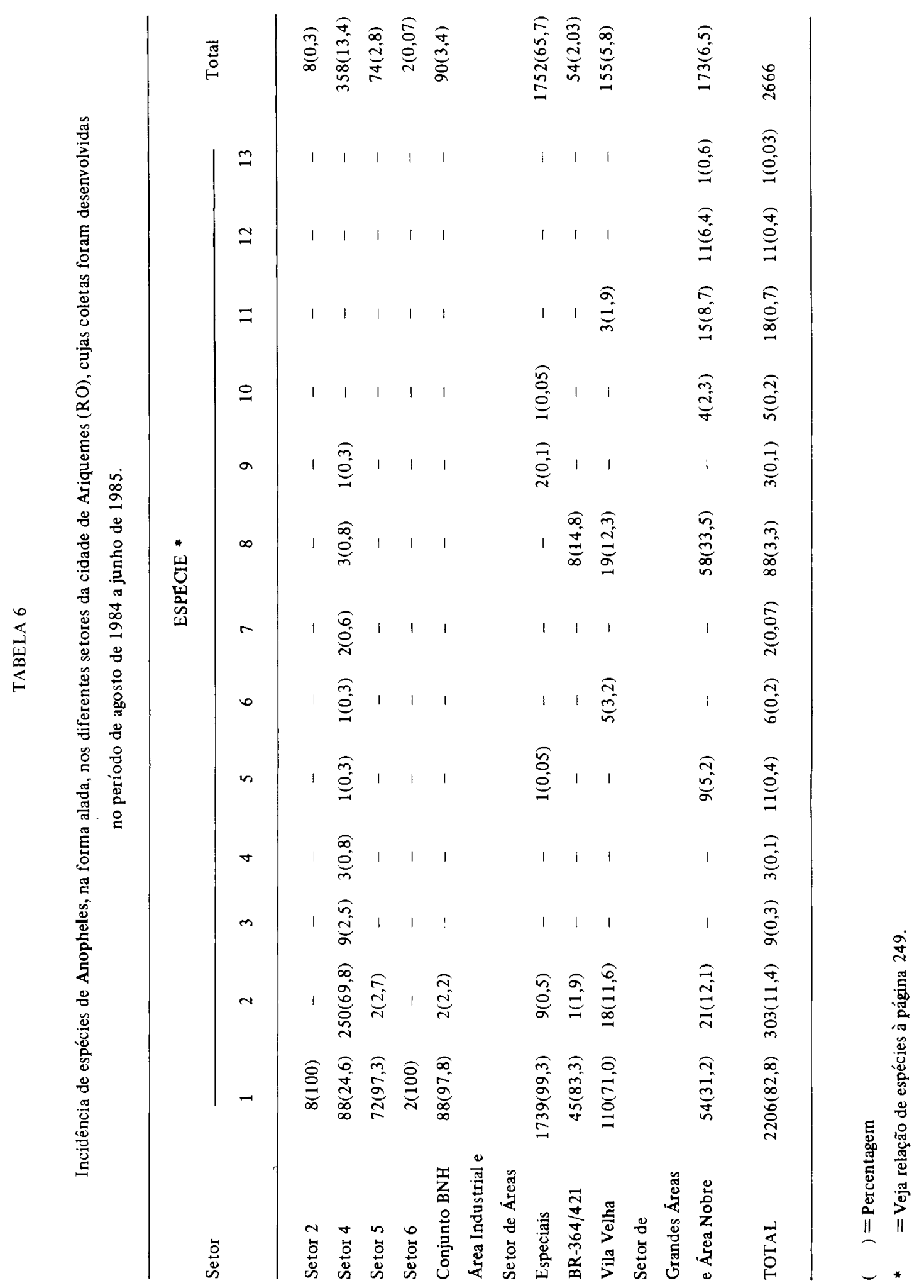


IADE1, W.P , SANTOS, J.M.M. dos; COSTA, W.L. de S. \& SCARPASSA, V.M. - Biologia de anofelinos amazônicos. XII. Ocorrência de especies de Anopheles, dinâmica da transmissão e controle da naalária na zona urbana de Ariquemes (Rondonia). Rev. Inst. Med. trop. São Paulo, 30(3):221-251, 1988

TABELA 7

Incidência de espécies de Anopheles, na forma alada, na estação de coleta Gurgel (Ariquemes - Rondônia).

\begin{tabular}{|c|c|c|c|c|c|c|c|c|}
\hline \multirow{2}{*}{ Data } & \multicolumn{7}{|c|}{ ESPECIE * } & \multirow{2}{*}{ Total } \\
\hline & 1 & 2 & 3 & 4 & 5 & 9 & 10 & \\
\hline \multicolumn{9}{|l|}{1984} \\
\hline $\begin{array}{l}\text { Agosto (início) } \\
\text { Agosto (final) } \\
\text { Setembro } \\
\text { Outubro } \\
\text { Novembro } \\
\text { Dezembro }\end{array}$ & $\begin{array}{c}561(89,0) \\
443(99,1) \\
312(100) \\
190(99,5) \\
35(100) \\
04(100)\end{array}$ & $\begin{array}{c}60(9,5) \\
04(0,9) \\
- \\
- \\
- \\
-\end{array}$ & $\begin{array}{c}06(0,9) \\
- \\
- \\
- \\
- \\
-\end{array}$ & $\begin{array}{c}01(0,2) \\
- \\
- \\
- \\
- \\
-\end{array}$ & $\begin{array}{c}01(0,2) \\
- \\
- \\
01(0,5) \\
- \\
-\end{array}$ & $\begin{array}{c}01(0,2) \\
- \\
- \\
- \\
- \\
-\end{array}$ & $\begin{array}{l}- \\
- \\
- \\
- \\
-\end{array}$ & $\begin{array}{c}630(34,2) \\
447(24,3) \\
312(17,0) \\
19 I(10,4) \\
35(2,0) \\
04(0,2)\end{array}$ \\
\hline \multicolumn{9}{|l|}{1985} \\
\hline $\begin{array}{l}\text { Janeiro } \\
\text { Fevereiro } \\
\text { Março } \\
\text { Abril } \\
\text { Maio (início) } \\
\text { Maio (final) }\end{array}$ & $\begin{array}{l}04(100) \\
07(100) \\
12(100) \\
25(100) \\
78(95,2) \\
89(100)\end{array}$ & $\begin{array}{c}- \\
- \\
- \\
- \\
02(2,4) \\
-\end{array}$ & $\begin{array}{l}- \\
- \\
- \\
- \\
- \\
-\end{array}$ & $\begin{array}{l}- \\
- \\
- \\
- \\
-\end{array}$ & $\begin{array}{l}- \\
- \\
- \\
- \\
- \\
-\end{array}$ & $\begin{array}{l}- \\
- \\
- \\
- \\
-\end{array}$ & $\begin{array}{c}- \\
- \\
- \\
- \\
02(2,4) \\
-\end{array}$ & $\begin{array}{l}04(0,2) \\
07(0,4) \\
12(0,6) \\
25(1,4) \\
82(4,5) \\
89(4,8)\end{array}$ \\
\hline TOTAL & $1760(95,8)$ & $66(3,6)$ & $06(0,3)$ & $01(0,05)$ & $02(0,1)$ & $01(0,05)$ & $02(0,1)$ & 1838 \\
\hline
\end{tabular}

( ) = Percentagem

$=$ Veja relação de espécies à página 249 .

TABELA 8

Incidência de espécies de Anopheles, na forma larvária, nos diferentes setores de Ariquemes (RO), cujas coletas foram desenvolvidas no período de agosto de 1984 a junho de 1985.

\begin{tabular}{|c|c|c|c|c|c|c|c|c|c|c|}
\hline \multirow{2}{*}{ Localidade } & \multicolumn{9}{|c|}{ ESPECIE * } & \multirow{2}{*}{ Total } \\
\hline & 1 & 2 & 5 & 6 & 8 & 9 & 10 & 11 & 12 & \\
\hline \multicolumn{11}{|l|}{ Setor $2 * *$} \\
\hline $\begin{array}{l}\text { Setor } 6 \\
\text { Igarapé das }\end{array}$ & - & $2(33,3)$ & - & - & $3(50,0)$ & - & - & $1(16,7)$ & - & $6(0,4)$ \\
\hline Naçöes-Gurgel & $481(54,9)$ & $220(25,1)$ & $14(1,6)$ & $1(0,1)$ & $25(2,9)$ & - & $18(2,1)$ & $116(13,3)$ & - & $875(52,4)$ \\
\hline Conjunto BNH & $264(84,0)$ & $14(4,5)$ & $3(1,0)$ & - & $16(5,1)$ & - & $2(0,6)$ & $15(4,8)$ & - & $314(18,8)$ \\
\hline $\begin{array}{l}\text { BR-364/421 } \\
\text { Setor de Grandes } \\
\text { Áreas - Área }\end{array}$ & $20(7,3)$ & $166(60,8)$ & $6(2,2)$ & - & $27(9,9)$ & $4(1,5)$ & $10(3,7)$ & $36(13,1)$ & $4(1,5)$ & $273(16,4)$ \\
\hline Nobre & $16(8,0)$ & $108(54,0)$ & $6(3,0)$ & $11(5,5)$ & $27(13,5)$ & - & $1(0,5)$ & $23(11,5)$ & $8(4,0)$ & $200(12,0)$ \\
\hline TOTAL & $781(46,8)$ & $510(30,6)$ & $29(1,7)$ & $12(0,7)$ & $98(5,9)$ & $04(0,3)$ & $31(1,9)$ & $191(11,4)$ & $12(0,7)$ & 1668 \\
\hline
\end{tabular}

constantes nas tabelas 1 e 2 , foi possivel traçar a extensão de penetração da espécie na área urbana, bem como mapear a sua ocorrência na periferia, representada pela região hachureada da figura 5. A observação desta figura possibilité verificar que existem diferentes graus de ocorrência da espécie na cidade, bem como áreas livres de anofelinos. Os Setores 1 e 3 estão 
TNDEI, W.P.; SANTOS, I.M.M. dos; COSTA, W.L. de S. \& SCARPASSA, V.M. - Biologia de anofelinos aniazónicos. XII. Ocorrência de espécies de Anopheles, dinâmica da transmissão e controle da malária na zona urbana de Ariquemes (Rondônia). Rev. Inst. Med. trop. Sāo Paulo, 30(3):221-251, 1988

\section{TABELA 9}

Incidência de espécies de Anopheles, na forma larvária, em pontos do Igarapé das Nações da cidade de Ariquemes ( $R O$ ).

\begin{tabular}{|c|c|c|c|c|c|c|c|c|c|}
\hline \multirow{2}{*}{ Data } & \multicolumn{8}{|c|}{ ESPECIE* } & \multirow{2}{*}{ Total } \\
\hline & 1 & 2 & 5 & 6 & 8 & 10 & 11 & 15 & \\
\hline \multicolumn{10}{|l|}{1984} \\
\hline $\begin{array}{l}\text { Agosto } \\
\text { Outubro (início) } \\
\text { Outubro (final) } \\
\text { Novembro (início) } \\
\text { Novembro (final) } \\
\text { Dezembro }\end{array}$ & $\begin{array}{r}58(26,0) \\
66(52,0) \\
162(72,3) \\
140(61,7) \\
198(88,4) \\
119(82,7)\end{array}$ & $\begin{array}{c}104(46,7) \\
34(26,8) \\
33(14,7) \\
45(19,8) \\
09(4,0) \\
04(2,8)\end{array}$ & $\begin{array}{c}12(5,4) \\
01(0,8) \\
01(0,5) \\
- \\
- \\
03(2,1)\end{array}$ & $\begin{array}{l}- \\
- \\
- \\
- \\
\cdots \\
-\end{array}$ & $\begin{array}{c}17(7,6) \\
- \\
- \\
- \\
07(3,1) \\
12(8,3)\end{array}$ & $\begin{array}{c}05(2,2) \\
- \\
- \\
02(0,9) \\
- \\
-\end{array}$ & $\begin{array}{l}27(12,1) \\
25(19,6) \\
28(12,5) \\
36(15,9) \\
10(4,5) \\
06(4,1)\end{array}$ & $\begin{array}{c}- \\
01(0,8) \\
- \\
04(1,7) \\
- \\
-\end{array}$ & $\begin{array}{l}223(17,2) \\
127(9,8) \\
224(17,3) \\
227(17,6) \\
224(17,3) \\
144(11,1)\end{array}$ \\
\hline \multicolumn{10}{|l|}{1985} \\
\hline $\begin{array}{l}\text { Fevereiro } \\
\text { Março } \\
\text { Abril } \\
\text { Maio } \\
\text { Junho }\end{array}$ & $\begin{array}{l}07(25,0) \\
07(31,8) \\
03(23,1) \\
12(44,4) \\
20(54,1)\end{array}$ & $\begin{array}{l}12(42,8) \\
05(22,7) \\
01(7,7) \\
11(40,8) \\
06(16,2)\end{array}$ & $\begin{array}{l}-- \\
\cdots \\
- \\
- \\
-\cdot\end{array}$ & $01(7,7)$ & $\begin{array}{c}01(3,6) \\
- \\
- \\
- \\
-\end{array}$ & $\begin{array}{c}- \\
- \\
- \\
04(14,8) \\
06(16,2)\end{array}$ & $\begin{array}{c}08(28,6) \\
10(45,5) \\
08(61,5) \\
- \\
-\end{array}$ & $\begin{array}{c}- \\
- \\
- \\
- \\
05(13,5)\end{array}$ & $\begin{array}{l}28(2,2) \\
22(1,7) \\
13(1,0) \\
27(2,0) \\
37(2,8)\end{array}$ \\
\hline TOTAL & $792(61,1)$ & $264(20,4)$ & $17(1,3)$ & $01(0,08)$ & $37(2,9)$ & $17(1,3)$ & $158(12,2)$ & $10(0,8)$ & 1296 \\
\hline
\end{tabular}

$(\quad)=$ percentagem

* $\quad=$ Veja relação de espécies à página 249.

classificados nesta última; a Área Industrial e Setor de Áreas Especiais, Conjunto BNH e Setor 5 são bairros de ocorrência elevada, havendo registro em até mais de $50 \%$ da área de cada um destes Setores. Este aspecto fica evidente quando são considerados, por exemplo, o Conjunto BNH em que de 22 pontos de amostragens, $73 \%$ foram positivos; a Área Industrial e Setor de Áreas Especiais onde $79 \%$ foram positivos em 19 amostrados. Para o Setor 6, a extensão deve ser maior, porém as capturas se restringiram apenas à área demarcada no mapa, uma vez que na época das coletas o Setor ainda estava sendo implantado. Para os Setores $2 \mathrm{e}$ 4 a ocorrência é unicamente periférica. Quando consideramos a margem esquerda da BR364, BR-421 e Setor de Grandes Áreas e Área Nobre verificamos que são áreas extensamente tomadas por A. darlingi.

Para uma avaliação da incidência de anofelinos por coleta, nos diferentes Setores da cidade, nas tabelas 10 e 11 são apresentados índices de anofelinos por homem/hora, os quais referem-se aos meses de agosto de 1984 a fevereiro de 1985 . De acordo com a localização física do Setor na cidade, foi possivel identificar Setores periféricos, cujos resultados estão na Tabela 10. Os dados da Tabela 11 são relativos aos Setores da área urbana mais central da cidade e também nestes Setores foi possivel classificar os pontos de coleta de perifericos ou internos, de acordo com a sua localização dentro de cada setor.

Nos resultados da Tabela 10 , na qual estão incluídos os pontos de mosquitos por homem/ hora, destacam-se os meses de agosto a outubro de 1984, com o registro de índices elevados de até 112 mosquitos por homem/hora. Os valores sào mais baixos nos meses de dezembro de 1984 a fevereiro de 1985, quando se constata queda 11 a densidade populacional. Esses índices tanbém demonstram redução nas médias por cada Setor e por mês. Para os indices dos Setores mais centrais em relação à estrutura física da cidade (Tabela 11), verifica-se que os pontos classificados de periféricos dentro desses Setores mostram, em média, valores mais elevados em relação aos pontos classificados de internos. Isto decorre da proximidade dos Setores em relação à mata circundante, como evidenciado na Figura 7 (Conjunto BNH-A e Setor 5-B). Os dados relativos ao Setor Industrial revelam valores elevados do índice mosquitos por homem/ hora, tanto para pontos periféricos, como para pontos internos. Este fato se explica pela mata remanescente que permanece no Setor entre os lotes, quando da realização das coletas. 
TADEI, W.P.; SANTOS, J.M.M. dos; COSTA, W.L. de S. \& SCARPASSA, V.M. - Biologia de anofelinos amazônicos. XII. Ocorrência de espécies de Anophetes, dinâmica da transmissão e controle da nalária na zona urbana de Ariquemes (Rondōnia). Rev. Inst. Med. trop. São Paulo, 30(3):221-251, 1988.

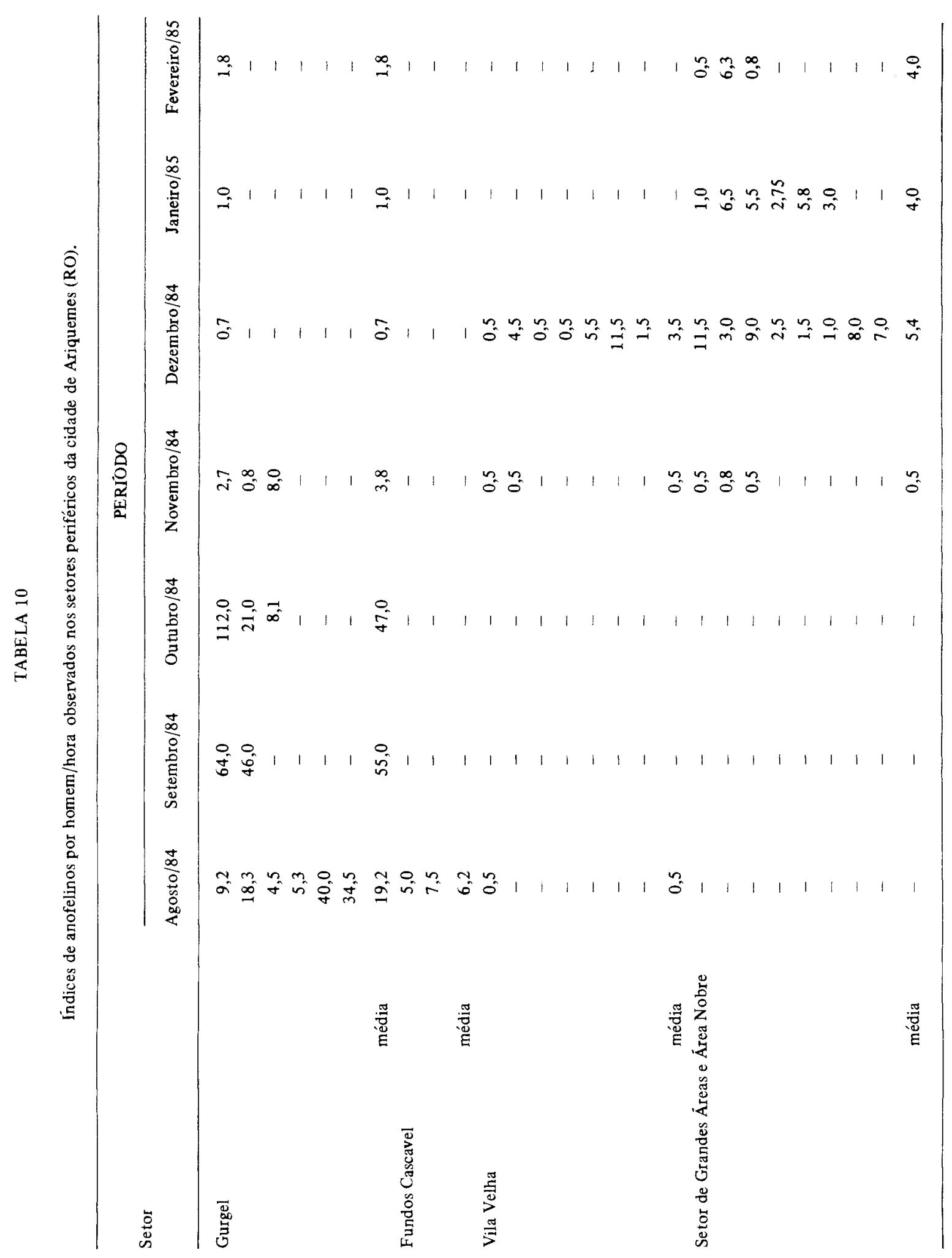


TADEI, W.P.: SANTOS, J.M.M. dos; COSTA, W.L. de S. \& SCARPASSA, V.M. - Biologia de anofelinos amazônicos. XIl. Ocorrência de especies de Anopheles, dinânica da transmissāo é controle da malária na zona urbana de Ariquemes (Rondônia). Rev. Inst. Med. trop. São Paulo, 30(3):221-251, 1988.

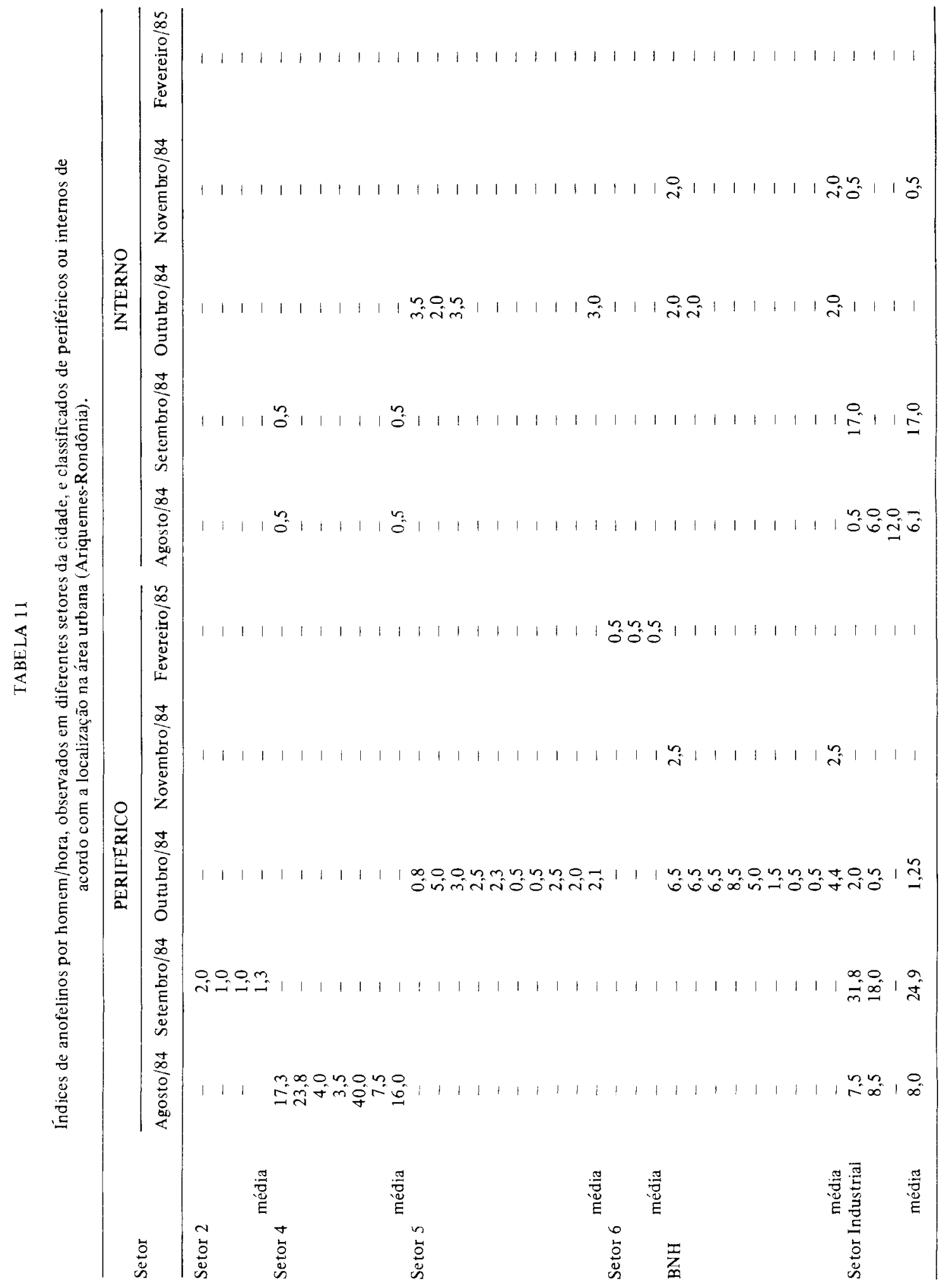


TADEI, W.P.; SANTOS, J.M.M. dos; COSTA, W.L. de S. \& SCARPASSA, V.M. - Biologia de anofelinos antazónicos. XII. Ocorrência de espécies de Anopheles, dirıàmica da iransinissão e controle da malária na zona urbana de Ariquemes (Rundônia). Rev. Inst. Med. trop. São Paulo, 30(3):221-251, 1988 .

A

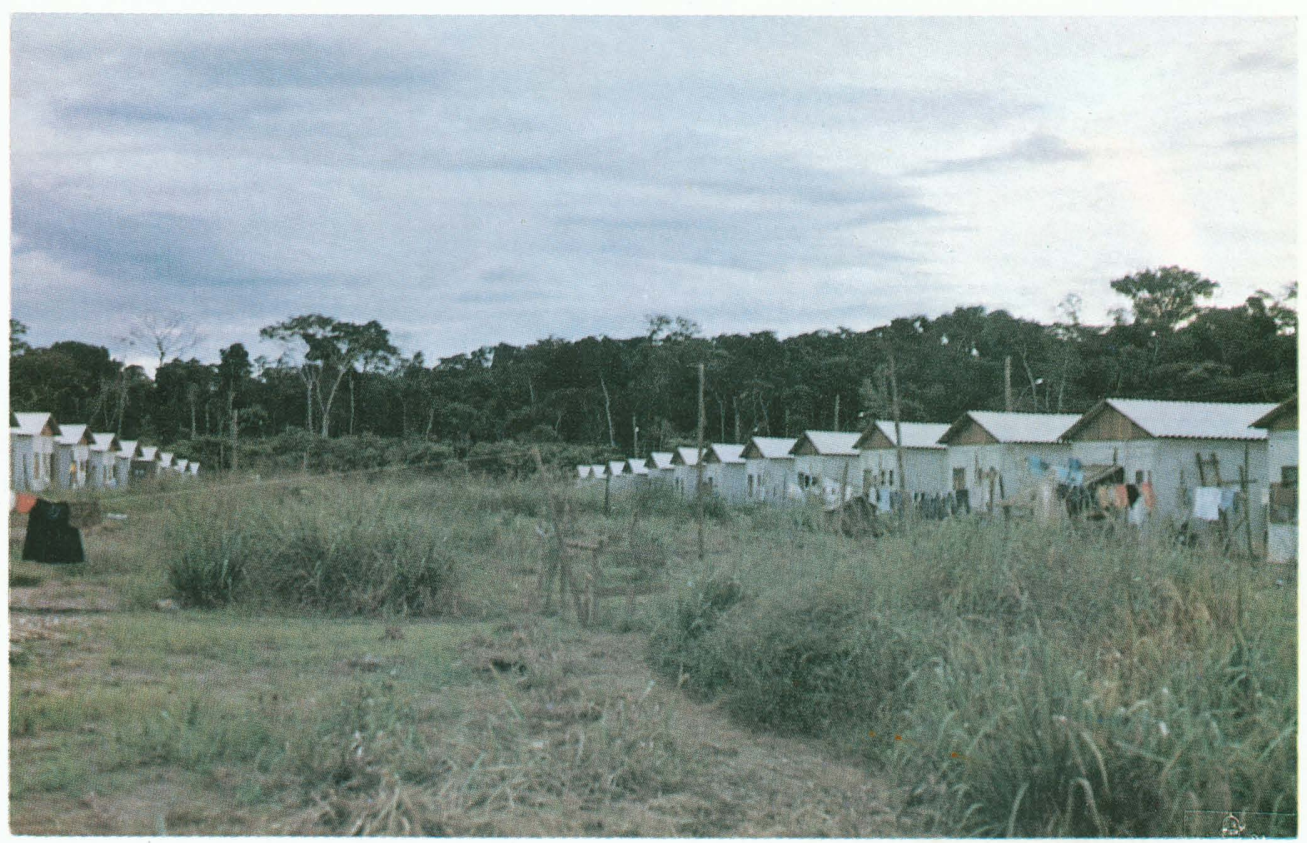

B

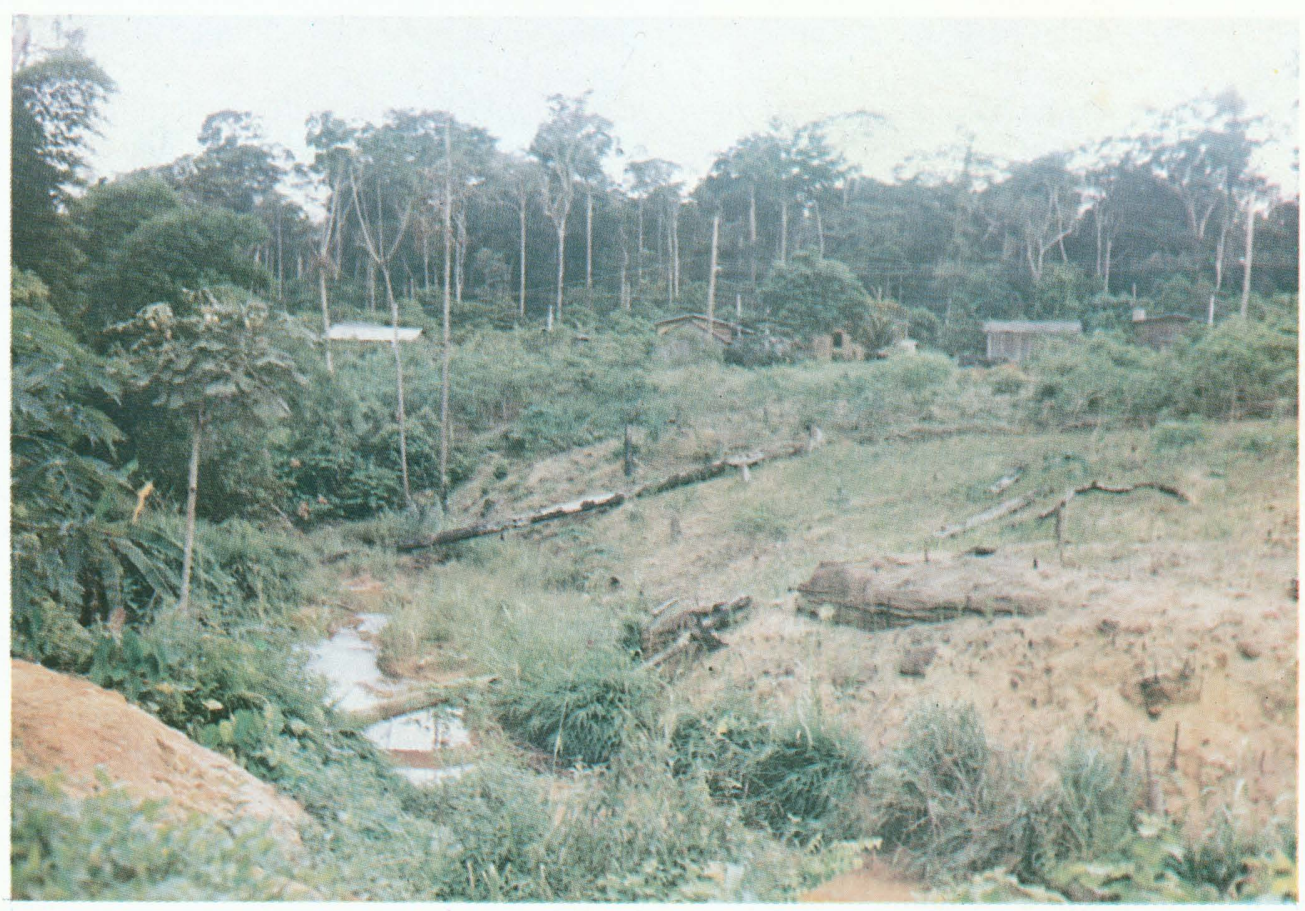

Fig. 7 - Conjunto BNH (A) e Setor 5 (B) e relação com a mata circundante. 
TADEI, W.P.: SANTOS, J.M.M. dos; COSTA, W.L. de S. \& SCARPASSA, V.M. - Biologia de anofelinos anazónicos. XII. Ocorrència de especies de Anopheles. dināmica da transminsào e controle da malária na corla urbana de Ariquemes (Rondònia). Rev. Inst. Med. trop. São Paulo, 30(3):221-251, 1988

No esıudo da infecção natural, foram realizadas dissecções de espécimes colecionados na Estação de coleta Gurgel e Conjunto BNH (Tabela 12). Durante as coletas, os espécimes foram separados de hora em hora, para o cômputo do índice de infeç̧ão, nos diferentes períodos. Foram dissecados 210 exemplares de $\mathbf{A}$. darlingi, sendo analisado o mesmo número de estômagos, e um número um pouco menor de glândulás salivares (199). Para o total, constatou-se o índice de infecção de $1 \%$, o qual se modifica quando são computados os mosquitos nos diferentes horários. No primeiro horário de observação $(18: 00-19: 00)$ o índice se repete, porém, o valor é duas vezes maior $(3 \%)$ para o período de 20:00 a 21:00 horas.

TABELA 12

Indice de infecção natural de Anopheles darlingi de amostras colecionadas em diferentes horários e em duas localidades (Gurgel e Conjunto BNH) da Zona Urbana de Ariquemes (RO), no período agosto de 1984 a junho de 1985.

\begin{tabular}{|c|c|c|c|c|c|c|c|c|c|}
\hline \multirow{3}{*}{ Examinado } & \multicolumn{8}{|c|}{ HORARIO } & \multirow{3}{*}{ Total } \\
\hline & \multicolumn{2}{|c|}{$18: 00-19: 00$} & \multicolumn{2}{|c|}{$19: 00-20: 00$} & \multicolumn{2}{|c|}{$20: 00-21: 00$} & \multicolumn{2}{|c|}{$21: 00-22: 00$} & \\
\hline & $\mathbf{N}$ & $\mathrm{P}$ & $\mathrm{N}$ & $\mathrm{P}$ & $\mathbf{N}$ & $\mathrm{P}$ & & $P$ & \\
\hline $\begin{array}{l}\text { Estômago } \\
\text { Glândulas }\end{array}$ & 96 & $1(1)$ & 77 & 0 & 32 & $1(3)$ & 5 & 0 & $210(1)$ \\
\hline Salivares & 93 & $1(1)$ & 74 & 0 & 32 & $1(3)$ & 4 & 0 & $199(1)$ \\
\hline
\end{tabular}

$(\quad)=$ Percentual de infecção $; \mathrm{N}=$ negativo; $\mathrm{P}=$ positivo.

\section{DISCUSSÃO}

O gênero Anopheles compreende um grupo complexo de espécies de interesse médico sanitário. Apenas através da intensa atividade entomológica é possível conhecer melhor o grau de diversidade e o indice epidemiológico das espécies, bem como avaliar a receptividade de uma área e, conseqüentemente, o seu nivel de vulnerabilidade. Para as espécies do gênero, o inquérito entomológico possibilita avaliar o potencial malarígeno, indicando o momento mais preciso de se desencadear as ações de combate que podem ser isoladas ou integradas, na dependência das condições ambientais.

No contexto brasileiro, o Estado de Rondônia se destaca por uma incidência elevada da malária e quando são comparados os índices de 1977 e de 1985 constata-se que a população do Estado cresceu em $366 \%$ e a incidencia da malária aumentou em $449 \%$. Conıudo, quando se consideram Municipios isoladamente verificase que pode ocorrer redução da prevalência da malária. No Projeto Machadinho, por exemplo (Município de Ariquemes), a freqüência da malária por P. falciparum diminuiu em comparavao ao ano anterior, em cerca de $20 \%$, pois apena $29 \%$ de casos foram registrados no primei- ro semestre de 1987 , em relação a 12.994 verificados em 1986. Ocorreu aumento na incidência de $P$. vivax pois o índice esperado de $50 \%$ foi observado no valor de $67,8 \%$, no primeiro semestre de 1987. Além do Projeto Machadinho, outras localidades podem ser citadas no Estado mostrando variações na prevalência da malária por $\mathbf{P}$. falciparum e $\mathbf{P}$. vivax, em comparação com o tamanho da população.

Desta forma, os estudos em espécies de Anopheles são de importância fundamental, quando são levadas em conta as campanhas de controle. Os padrões comportamentais, bem como as condições de adaptação, constituem-se em parâmetros relevantes pelas interrelações que apresentam com as medidas a serem adotadas na redução do contato homem/vetor.

Os dados do inquérito entomológico para espécies de Anopheles, realizado na zona urbana de Ariquemes, proporcionaram o conhecimento da diversidade específica, bem como da extensão de ocorrência de $\mathbf{A}$. darlingi e de outras espécies de anofelinos na cidade e, ainda, informaçōes sobre aspectos biológicos das espécies, importantes nas estratégias de controle.

Tomando-se a ocorrência de A. darlingi, verifica-se que a espécie foi registrada em toda a perileria da cidade, tendo pontos de maior ou 
TADEI, W.P.; SANTOS, J.M.M. dos; COSTA, W.L. de S. \& SCARPASSA, V.M. - Biologia de anofelinos amazonicos. XII. Ocorrência de espécies de Anopheles, dinâmica da transmissão e controle da málíria na yona urbana de Ariquemes (Rondônia). Rev. Inst. Med. trop. São Paulo, 30(3):221-251, 1988.

menor penetração, conforme o Setor considerado. Na figura 5, a área delimitada expressa os pontos que foram positivos para a ocorrência de A. darlingi, indicando os Setores de maior risco da malária. Com base nos pontos positivos e negativos foi demarcada a área de registro do vetor, possibilitando dimensionar a amplitude de penetração na cidade, para os diferentes Setores. Contudo, as linhas traçadas nào refletem um espaço fixo e definitivo, uma vez que a sua dimensão é variável de acordo com as flutuaçôes das populações de anofelinos da periferia, sujeitas às modificações ambientais e variaçóes estacionais. O espaço dimensionado pode ser tomado como uma expressão máxima de ocorrência dos anofelinos na área urbana, para o periodo de amostragens. Os índices de mosquitos por homem/hora demostraram que a exposiçào é acentuadamente maior nos pontos periféricos, quando comparados com os índices obtidos em pontos internos.

Portanto, com base nas delimitaçòes constantes da figura 5, podemos tecer as seguintes consideraçoes sobre os riscos de malária na cidade de Ariquemes: Setores 1 e 3 - áreas livres de malária; Setores 2 e 4 - áreas com riscos na periferia; Área Industrial e Setor de Áreas Especiais, conjunto BNH, Setor 5 e Vila Velha áreas de alto risco da malária. Estes mesmos Setores foram ressaltados, por TADE[36, quando de comunicação preliminar sobre a ocorrência de anofelinos no Município de Ariquemes.

Os Setores de maior risco, compreendidos pela Área Industrial e Setor de Áreas Especiais, Conjunto BNH e Setor 5, estão classificados desta forma com base nos resultados do inquérito entomológico que evidenciou a importância do Igarapé das Nações no desenvolvimento do ciclo reprodutivo dos anofelinos. Em decorrência da proximidade desses Setores com o Igarapé, o qual é tomado por uma mata primária remanescente que margea a cidade neste ponto (figuras 2 e 7), constatou-se que essas áreas estão mais suscetíveis à migração dos anofelinos, para o repasto sanguíneo. De acordo com os dados do Inquérito Entomológico, para as formas imaturas, o igarapé apresenta uma incidência alta de anofelinos, principalmente A. darlingi (tabelas 5, 8 e 9), indicando ser o ponto de desenvolvimento das formas imaturas das espécies de Anopheles, até a emergêneia do imago.

Desde que não existam outras coleçôes hídricas nas proximidades dos três Setores para reprodução das espécies, verifica-se, com base no Inquérito Entomológico, que o ciclo de desenvolvimento dos anofelinos se completa na forma abaixo descrita e que tem reflexos no esquema de transmissão da malária, na área urbana:

1. Mata primária - possivelmente utilizada para permanência dos adultos até a ocorrência da cópula e para o desenvolvimento do ciclo gonotrófico, após o repasto sanguíneo. Abrigo natural para permanência dos adultos, após repastos subseqüentes.

2. Igarapé das Nações - Criadouro natural dos anofelinos, constituindo sítios de oviposição e desenvolvimento dos estádios larvais, até a emergência do imago.

3. População humana da periferia da eidade Local do repasto sanguineo (fonte protéica) das populações de anofelinos, principalmente A. darlingi, para o desenvolvimento do ciclo gonotrófico.

Portanto, os dados do Inquérito Entomológico possibilitaram diagnosticar o ciclo de desenvolvimento das populaçoes de anofelinos existentes nessas localidades, identificando-se os pontos de: a) permanência dos alados; b) de desenvolvimento das formas imaturas, e c) da fonte protéica. O conhecimento desses parâmetros é relevante para se estabelecer medidas de controle da malária, pois permite identificar em que(ais) nivel(eis) as medidas seriam mais eficientes no controle do vetor, ou seja: 1) a nível do alado, quando ainda na mata ou após o repasto sanguíneo; 2) a nível das formas imaturas, ainda nos estádios larvais; 3) a nível do alado, quando do contato homem/vetor, no momento do repasto sanguíneo.

No controle da malária na área urbana de Ariquemes, objetivando-se o vetor na situação demonstrada pelos dados do Inquérito Entomológico, são importantes, em primeiro plano, as medidas de proteção individual (telagem das casas e uso de mosquiteiros), que apresentam efeitos imediatos na redução do contato ho$\mathrm{mem} /$ vetor. Paralelamente, o manuseio ambiental constitui uma medida básica pois está envolvida a alteração do habitat de modo que as espécies de Anopheles desloquem seus sítios de procriação. Como ressaltou TADE[34, 36, em comunicaçôes preliminares sobre o controle da malária urbana em Ariquemes, medidas deste porte deverão atingir o controle do vetor, em todos os níveis do ciclo biológico. 
TADEJ, W.P.; SANTOS. I.M.N. dos; COSTA, W.L. de S. \& SCARPASSA, V.M. - Biologia de anotelinos arrazonicos. XI! Ocurréncia de

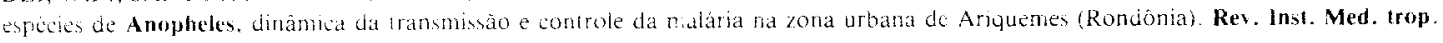
Sato-Paulo, 30(3):221-25], 1988.

En relação às medidas de proteçâo individual, os dados da literatura evidenciam a sua eficiência, como relatado por TADEl et al." na Vila Rasgào (SP) instalada em 1925 para funcionários da Hidrelétrica da Light, em que se verilicou a erradicaçào da malária, após a telagem das casas. Também se constata o valor dessas medidas individuais quando se analisa literaturas referentes à construção da Ferrovia Madejra-Mamoré e de outos eventos na Amazônia.

Os registros de autoctonia da malária revelam indices elevados para as áreas de penetração de A. darlingi na cidade. Para a Área Industrial e Setor de Áreas Especiais, a migração dos anofelinos é facilitada pelos arbustos remanescentes que permanecem na área possibilitando a migração até atingir áreas próximas aos Setores 1 e 3 . Esta área de penetração dos anofelinos, partindo do Igarapé das Nações, denota uma extensão de migração do mosquito que se estende até cerca de 2.000 metros, a partir do criadouro (neste caso admitido ser o Igarapé das Naçōes). Esses dados estão de aco do com a literatura que registra um raio de vô para $\mathbf{A}$. darlingi de aproximadamente 2.000 metros 14,15 podendo atingir ate 5.000 metros, a favor do vento 13,41 .

Levando-se em conta a migração do vetor. é possivel interrelacionar a estrutura física da área urbana de Ariquemes e suas implicaçôes com a transmissão da malária. Conforme pode ser observado na figura 1 , a qual inclui a constituição da cidade en detalhes, verifica-se que as alamedas formam uma área verde e que, possivelmente, tiveram sua influência na incidência da malária urbana, quando da fundaçào da cidade em 1976. O aspecto atual das alamedas consta na figura 8 (fotografia aérea recente da cidade) e observa-se que as mesmas, no momento, encontram-se praticamente desmatadas, existindo arbustos esparsos e o solo com uma cobertura de vegetação rasteira, geralmente constituida de gramineas. No entanto, na época em que a cidade foi fundada, as alame-

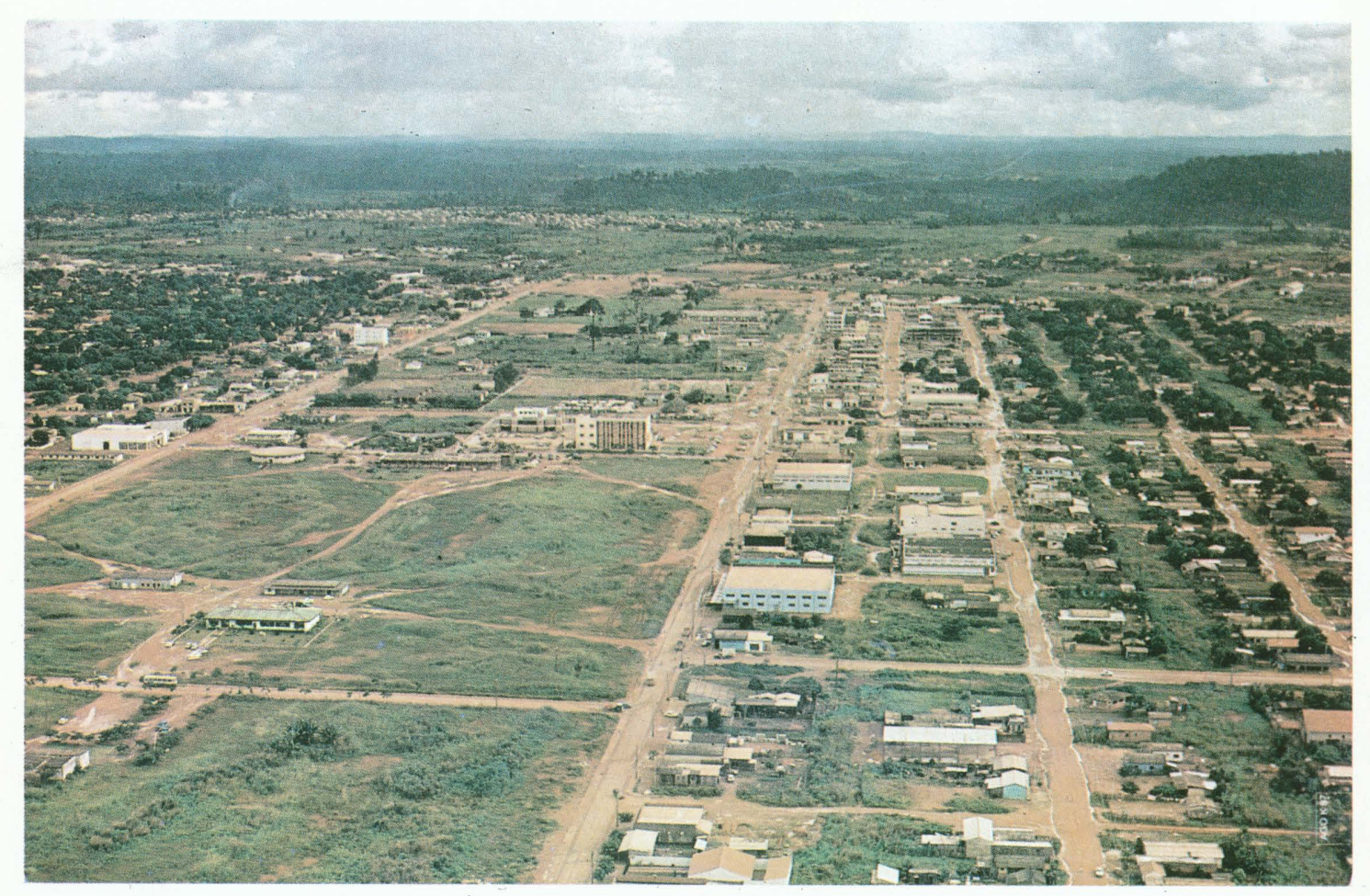

Fig. 8 - Cidade de Ariquemes - aspecto atual das alamedas. 


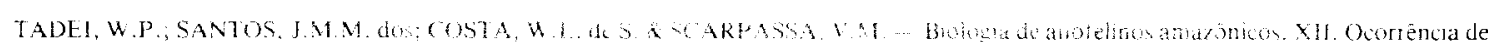

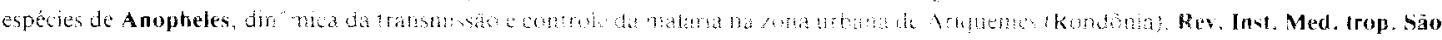
Puulo, 30(3):22) 251, 1988

das do Setor 1 apresentavam a mata primária e esta constituía um extrato arbóreo contínuo com a mata da periferia da cidade. Esta disposição - mata primária das alamedas e mata primária circundante, em continuidade cidade adentro, facilitava a migração dos anofelinos para o contato homem/vetor, contribuindo assim, para uma autoctonia alta da malária urbana. Também, como as casas foram construidas com as dependências anteriores (alpendre, salas, dormitórios) para as alamedas, esta distribuição proporcionou um contato maior ainda com a mata e, conseqüentemente, com os anofelinos. A soma desses eventos foi o fator agravante da prevalência elevada da malária urbana em Ariquemes quando a cidade foi iniciada.

Amopheles darlingi apresenta raio de ,o extenso e a periferia da cidade mostra popula çöes em densidade relativamente alra, alem de estar em contato com a mata (fig wa 7 , ofere cendo elementos que facilitam a migracao 0 vetor. Nestas condiçes, para se redurit a fo valéncia da malana umana, lomam-e yemen. tes medidas que objetram a reduac da dent. dade populacional de anofelinos na periteria. para conter o processo migratorio nosids atua criticas. O controle dos criadouros nas proximi. dades é una medida fundamental na conencano da densidade, empregando-se o manuscio do ambiente para alteraçào do habilat natura! da reprodução, controle biológico e, em ultina instância, a utilização de larvicidas.

No controle do processo migratório e do contato homem/vetor ressalta-se a importância de um cinturão de proteção entre a área urbana e a mata circundante, conforme pronosto por TADEI et al. ${ }^{34}$ para a área residencial na Hidrelétrica de Tucurui, que tambem apresentava $\mathbf{A}$. darlingi na periferia. Este cinuräo seria constituído de uma vegetação não detısa, permanecendo no mesmo árvores de grande porte arbustos maiores; poderia existir tambem neste cinturão pequenas áreas de pastagens, dependendo das condicoes do solo. Fstas ultimas tornam-se relevanies por terem a caracteristica de uma proteção biológica às areas residenclati, sendo fonte alternativa rara a alvidade thomatófaga dos anofelinos, incentriande o desenvol vimento da zoofilia.

Esta área de proteça en tondo ta meriteria de Ariquemes poderia osciar ome l.owe 1.500 metros, segundo-se a mudanomaty iexposta por TADEl et al. "com base nas inser- vaçoes do comportamento de A. darlingi, em pontos de estudo da BR-174 (Manaus/Boa Vis1a). Os autores descresem que a faixa de segu. rança, ná medida acima citadả, possivelmente seja suficiente para isolar a populaçào humana do contato com as populações de anofelinos da periferia, levando-se em conta as estimativas de migraça do vetor verificadas naquela rodovia.

Dentre as medidas de controle das espécies do subgènero Kerteszia, no sudeste do país, para regiôes endêmicas da malária, foi sugerido lambém uma área de proteção em torno dos centros populosos":. Como essas espécies têm seus silios de reproduçâo nas bromélias, neste caso a jiea de proteção seria desprovida das bromelia: com remoção manual das espécies eplitias e terrestres; for ainda indicado o emprego de substancias herbicidaste.

Enforando-se a Anazonia como um todo, e pussivel delectar inumeras areas com caracteristica semethanes área do Municipio de Ariqutmes cuas condiçoes ambientais são extre-

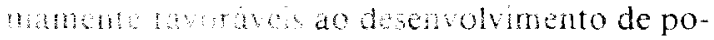
phace de 4. Haringi, on densidade elevada.

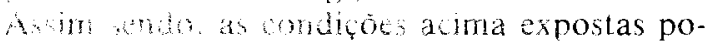
den se mmadas como modelo para a região Anaronic na instalaça de Centros urbanos. Eutes derems sempre estar envolvidos por uma area le proceso objerivando o isolamento da populaça humana periférica do contato com o velor. Durante o crescimento das cidades, este cinturào de proteção tambem seria ampliado coneomitantemente à area urbana.

Nesta mesma otica, para a exploração da area rural, as mesmas premissas seriam verdadeiras, ou seja, a localizaçäo das casas deveria ocunar o ponto mais alto do terreno distancundo-se ao máximo das coleções hídricas, as quais, naturalmente, nessas regiões se constituem nos criadouros dos anofelinos. A localizacão no ponto mais alto contribui para um distanciamento maior dos sítios de reprodução, diminuindo a probabilidade de contato homem/vetor. Residencias nas proximidades dos criadouros mostra densidade anofélica muito maior em comparaçào com aquelas situadas em pontos mais clavados e mais distantes dos criadouros. Alem dess aspecto, é de fundamental imporiância a exploraçâ da área a ser utilizada para a agricultura c/ou pecuária de forma diametralmente à casa e em cículos concêntricos a ewa. A ruso do deste pacedimento gera naturabrut o yma faika de procecáo em torno da residura áli a rural, de crescimento circular. 


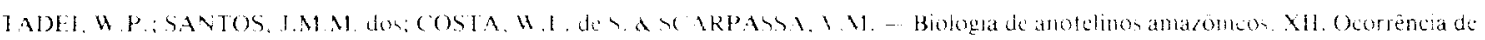

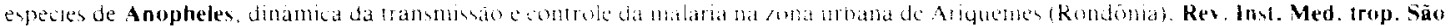
Paulo, 30(3):221-251, 1988

Esta faixa é ampliada se no ponto de contato entre dois lotes as residências ficarem próximas e ocuparem o centro de exploração.

Un aspecto a ser destacado en condiçōes. urbana, com base nas áreas delimitadas na figura 5, é a faixa de proteção que pode ser demarcada para a aplicação do DDT. Desde que os dados do inquérito entomológico sejam obtidos en época de inverno e de verăo, cobrindo portanto periodos de maior e menor densidade das populaçòes de anofelinos, a faixa pode se restringir a Setores periféricos, não sendo necessário dedetizar os Setores 1 e 3 e parte do 2 e 4. Estas áreas, ocupando posição central urbana, constituem-se em áreas livres de anofelinos, sendo desnecessária a aplicaçào do inseticida. $O$ restante da cidade e imediações, face a presenţa acentuada dos anofelinos, devem continuar no esquema normal de aplicações semestrais. Este fato é especialmente verdadeiro para a Area Indusurial e Selor de Áreas Especiais, Conjunto BNH, Setor 5 e Vila Velha, que oferecen aloo risco.

Os dados sobre densidade populacional de anotelinos, obtidos em diferentes épocas do ano (Tabelas 7 e 9), evidenciaram que ocorre variaçào tanto para as tormas aladas como para as formas imaturas. A observaço dos resultados possibilita verificar que ha correlaçào entre reducào da densidade populacional com o periodo de inverno. Esta correlatcáo e mais evidente para as formas aladas do que para as imaluras; para estas últimas, os dados revelaram uma cerla estabilidade, quando consideramoso total de espécies. No inicio do periodo de inverno, contudo, já no mês de dezenıbro de 1984 constatou-se reduçào na densidade. Estes resultados estão de acordo que em regiós tropicais as variaçoes na densidade, correlacionadas com mudanças estacionais, em populaçōes de mosquitos, podem ser afetadas pela disponibilidade de sitios de reprodução que estão en relação direta com o padrào do regime pluvial centre outros? 31. 33. 41. 4). Dados sobre o comportamento das populaçoes de anofelinos da região evidenciam que no período de inverito os sitios de reprodução são deslocados dos crialinuros permanentes, situados nos lagos i lagaa funto as margens dos rios a no proprio leilo, para criadouros temporários localizados en? meio a mata, constituidos pelas inumera poras e lagoas que se formam neste periodo.

A disponibilidade de sitios da renroducio acima mencionada, que aumenta no incio do periodo de inverno, possibilita ampliar a extensão de ocorrência de anofelinos, com reflexos na prevalência da malárı, pois proporciona maior contato homem/vetor. Isto decorre do fato de que em regiòes onde os criadouros permanentes estão distanciados das áreas residenciais, na época de inverno, pela formaçào de criadouros temporários, estes ficam em uma relação de influência com as habitaçoes nas proximidades. Este aspecto de ampliação da área de ocorrência de anofelinos, na época de inverno, especialmente para $\mathbf{A}$. darlingi, foi enfatizado por GALVÄO:, em estudos realizados na cidade de Belém (Pará) e discutidos por DEANE para outras localidades da Amazo. nia. Os dados obtidos em Ariquenes possibilitaram constatar reduçăo na densidade larvária, no periodo de inverno, que se inicia mais tarde en relacão à densidade dos alados, em tormos totais Porem, guando se examina as trequências das especies individualmente (Tabela 9), constata-se que A darlingi tenn comportamento oposio at A. triannulatus. Esta ultima, mostra reduçào a partir de agosto de 1984 a alados fo ram capurados apenas nas primeiras amostragens. Para A. darlîngi no entanto, os dados relativos a alados mostraram reduçào continua a partir de agosto de 1984, enquanto que as larvas, para o mesmo periodo, apresentaram aumento, atingindo o pico maior em novembro de 1984, para entào começar a reduça na sua incidentia. Como a estação de capturas fica próxima ao Igarapé das Naçōes, estes resultados podem ser interpretados considerando-se as aplicaçoes do DDT, realizadas semestralmente no começo do período. É provável que. embora haja densidade elevada de anoteinos no inicio do semestre (agosto de 1984), un número baixo de fémeas consegue conpletar o ciclo reprodutivo, apos o repasto. Este numero aumenta posteriormente, face à reduça da messão do inseticida, que gradativamente vaj sendo relirado das paredes e vegetaça circumante, no decorrer do semestre. Neste esquema, tmin numero maior de lentea provavelnente conseguiriam alcancas " criadouro e deixar descendentes. apos o rasto sunguinco. Por outro ado, uma alta densidade lar ária em novembro. para !n correspondente reduça dos atados pode ser

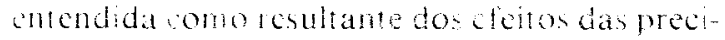
macoes pluviometricas, propras da fpoca de inverno, que chegam a impedry o desiocament. dos alades para o repasto sangúneo. A parit deste periodo, at demodale baia em ambas as 
TADEI, W.P.; SANTOS, J.M.M. dos; COSTA, W.L de S. \& SCARPASSA, V.M. - Biologia de anofelinos amazonicon. XII. Ocor rencia di

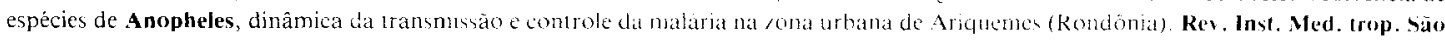
Paulo, 30(3):221-251, 1988.

formas, en decorrência das alteraçōes ambientais provocadas pela época de inverno.

Ainda em relação à ampliação dos sítios de reprodução na estação das chuvas, os dados sobre a estrutura genética de populações naturais de A. darlingi da Amazônia, obtidos com base na análise do polimorfismo cromossômico, evidenciam que a espécie é mais polimórfica neste período. Estes resultados foram interpretados como uma estratégia adaptativa da espécie, que lhe confere uma plasticidade adaptativa maior, tornando-a mais apta para explorar os diferentes ambientes que se formam na época do invernot). Na Amazônia, portanto, para populações naturais de $\mathbf{A}$. darlingi, são esperadas modificações na densidade populacional da espécie, correlacionadas a mudanças estacionais do inverno e de verão. MORAN ressalta que em florestas pluviais tropicais, populações animais sofrem mudanças na estrutura e tamanho em decorrência de alterações estacionais. Por outro lado, WOLDA \& GALINDO +2 relatam modificações na densidade em populações de insetos de área em que aparentemente não há estaçòes bem marcadas.

Os resultados sobre a atividade de picar referem-se às coletas realizadas com seis horas de observação, desenvolvidas em pontos dos Setores 2 e 3 e da Vila Velha (Tabela 3), e com doze horas em pontos periféricos da cidade Gurgel, Fazenda Boa Vista e Reservatório do INCRA (Tabela 4). Constatou-se, para os pontos com seis horas de observação, localizados na área mais central da cidade, que a atividade se encerra em torno das 21-22 horas, não mais sendo coletados anofelinos nos horários 22-23 e 23-24. Considerando as espécies com freqüências acima de $1 \%$ - A. darlingi, A. triannulatus, A. oswaldoi, A. mediopunctatus e A. evansae - verificou-se que, com exceçào da penúlt jma, as demais apresentavam o pico de maior atividade no primeiro horário de observação (18-19 horas). No entanto, para os pontos periféricos, os dados evidenciaram que A. darlingi apresentava atividade durante toda a noite, com um pico no início, entre 18-22 horas, e outro no amanhecer, menos intenso, entre 4-6 horas da manhã. As demais espécies foram registradas apenas nas primeiras horas de coleta, porém A. oswaldoi e A. triannulatus também foram colecionadas ao amanhecer. Esses resultados estão de acordo com o padrão observado por TADEI et al. ${ }^{34}$ para as espécies de Anopheles da região de Tucuruí, porém, naquela re- giào, a atividade no início da noite era mais intensa no segundo horário de observação (19-20 horas). Considerando-se A. darlingi, constatou-se o padrão bimodal, com atividade continua, o qual é registrado para populações de diferentes origens geográficas da Ama-

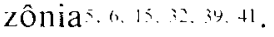

Por outro lado, as espécies de Anopheles podem ser caracterizadas pelo padrào da atividade de picar por meio de observaçōes contínuass ${ }^{1-}$. 26. 3.9. No entanto, este padrào está em relação com o ritmo circadiano, porém pode ser afetado por fatores genéticos e ambientais, sendo que estes últimos, em manifestação extrema, podem até impedir a atividade, apesar da indicação do ritmo circadiano $1.4,13,38$. Ainda, em espécies polimórficas para inversões cromossômicas, podem ser observadas variaçōes em portadores de diferentes constituições genéticas. Este aspecto tem sido registrado em diferentes espécies de Anopheles, em relação ao ritmo circadiano, frequiencia de cruzamentos, período de pupação e de emergência do imago, e na observação de arranjos gênicos especificos a variaçōes quanto à exofilia e endofilia $\cdot x, 4,10,23,24,25$.

Apesar de múltiplos fatores interferirem no padrão comportamental da atividade de picar das espécies de Anopheles, conforme enfocado anteriormente, na região Amazônica este padrão pode ser caracterizado considerando-se: 1) o ambiente natural e 2) as áreas ecologicamente alteradas da região. No primeiro, constata-se que o padrão comportamental das espécies para a atividade de picar mostra um espectro contínuo de atividade que se estende durante o dia e durante a noite e, com freqüência, mostra um pico de atividade ao anoitecer e outro ao amanhecer de menor intensidade. Este padrào é registrado em meio à mata primária ou en áreas em estreita relação com os criadouros. Também este padrào pode ser observado en habitaçoes localizadas na orla da mata primária ou mesmo quando a habitação está próxima às coleçoes hídricas que apresentam relação com mata primária remanescente ou mesmo secundária. Ainda, esta atividade contínua pode ser verificada na época de inverno, em áreas em que normalmente não é regisırada atividade diurna; apenas noturna. Isto decorre do fato de que, neste período, com a dispersão dos sítios de reprodução dos anofelinos, estas áreas passam a ter uma relação muito estreita com os criadouros que foram disseminados a partir dos permanentes da época do verão. 


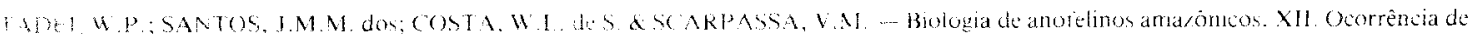

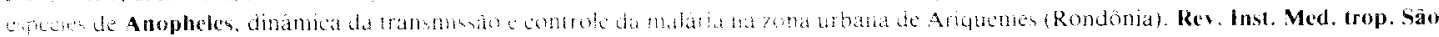
Patula $30(3): 221-261,198 \%$

Quanto à areds ecologicamente alteradas, iuas modalidades podem ser identificadas areas com modificaçóes estáveis e àreas recentemente alieradas. Estas duas situaçöes podem ser encontradas en regióes de ocorrència dos grandes Projetos de Colonizaçào da Amazónia. As arcas estáveis referem-se as localidades já colonizadas, encontrando-se estabilizadas a agricultura e a pecuária. As áreas recentemente alteradas envolvem as localidades em implantacào, cujas modificaçōes estào em curso, com desmatamentos e ocupaçào da terra em desenvolvimento. Nestas duas modalidades, padròes diferentes de comportamento das espécies de Anopheles podem ser detectados quanto à atividade de picar. Como os assentamentos ocorrem as margens das rodovias e vicinais nos Projetos, una area é desmatada entre a via de acesso e floresta primára, variando, freqüentemente, sute 500 e 1.000 metros. A habitaça é instalahat julo à rodonia. Nesta disposiçar, em re. yoes de ocorrência de anofelinos, especialmenif A. darlingi, molala-se um exquema en qui uma lraça da populaça de anolelino nigra

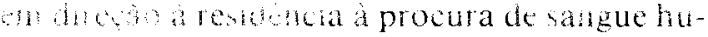
manes. Apon o mat on inciado o processo de

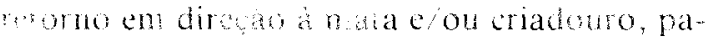
ra desenolmento do cido gonotólice onmicao lns as de desmatamento recente

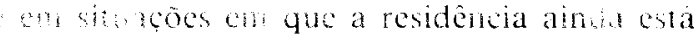
mollo proxma da mata con cotado un paUras de midad dinn o notumo. A motida cm que acupaso do terreno vat ocorrendo a atividade diurna vai se extimenndo proporcionalmente. Na cienendencia do ritmo de ocupacão e distancimenco da nata em relaçào à casa, a atividade wi se restringindo ao periodo noturno. En arcas esiabilizedas, com explora câo com cerca de $3-5$ anos, sm que a distância residencia - mata $i$ de aproximadamente 500 80 metros, e possive! detesar que a atividade fica werita apenas a periodo noturno sendo mais intensa no brepusculo. Na epea de inver-

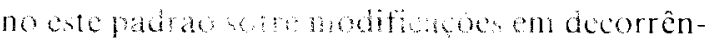
cia chos inumeros chadouro, comporarios que se

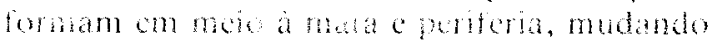
" esquema be isolameno -.. reventemata

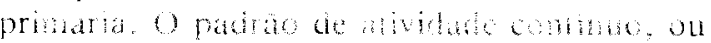

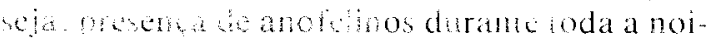
$\therefore$. sra na dependencia da densidate popula cional, interrerlacionada do distanomento residência/mata, pois, este último, muiro proeminente. levara a uma exposicas nilin dos anofelinos, no momento do repmeto pristade po. pulacional baixa, freqüentemente, mostra un padrão de atividade que se restringe apenas ao inicio da noite, encerrando-se entre 20-21 horas.

Considerando-se os dados sobre a atividade de picar, obtido em pontos periféricos e internos em relação à área urbana de Ariquemes, é possível identificar dentre os padrões descritos, que os pontos internos, com baixa densidade de mosquitos (menores valores dos índices de mosquitos por homem/hora) se enquadram no padrão de áreas alteradas com densidade populacional baixa. De forma similar às áreas de colonizaçào, para os pontos internos, o vetor tem que migrar uma extensão maior e um número baixo atinge os Setores internos, manifestando o padrão restrito às primeiras horas da noite. Para os pontos periféricos, a atividade foi contínua durante toda a noite mostrando o padrão em que a residência está em relação com a mata primária e/ou criadouro. De fato, os locais em que as medidas foram obtidas durante toda a noite são representados por residências localiladas proximas ao Igarapé das Naçōes, junto à uma mata primária remanescente. Nestas condiçoes, espera-se um padrào contínuo, conforme descrito e, na época de inverno, até o retorno da andidado diurna, en decorrência do aumento da densidade populacional. Este parâmetro não foi observado sistematicamente nesto trabalho, mas foram registrados anofelinos com atividade diurna nos pontos de observação dessas localidades.

Os dados da literatura sobre espécic de Anopheles vetoras da malária na Amazônia, obtidos pelo método usual de dissecçào para investigação de oocistos a esporo\%oitos possibilitaram relacionar diferentes espécies como vetoras (entre outras $1,14.15,1 \%, 3, \ldots, 3)$. Anopheles darlingi é mencionada como principal vetor, responsável pela transmissão no interior e de 4/5 em toks o paisin. Os dados obtidos em Ariquemes, também pela técrica de dissecção, possibilitam citar $\mathrm{A}$. darling como transmissor na cidade. Confome mostram os dados da Tabela 12. Coi encontiato un nivel de infecção de $1 \%$, lanto para a presença de esporozótos como para oocistos. Um aspecto interessante a ser ressaltado nestes resultados, ainda, é que a infeccào é mais elevada no horário de 20-21 (3\%). Este parâmetro possibilita questionar o problema de estrutura ctária en populaçoes naturais de Anopheles, cujos dados preliminares têm cvidenciado uma frcquência maior de fêmeas 
TADEI, W.P.; SANTOS, J.M.V. dos; COSIA, W.L. de S. \&SC ARPASSA, V.M. - Biologia de anofelinos amazônicos. XII. Ocorrência de espécies de Anopheles, dinânica da tranbmissào te cont role da maliuria na zona urbana de Ariquenes (Rondonia). Rev. Inst. Med. trop. São Paulo, 30(3):221-251, 1988.

nuliparas nos primeiros horários e as oniparas predominantemente nos horários mais tardios. Neste caso, estas últiınas teriam maior importância epidemiológica considerando-se a maior probabilidade de estarem infectadas, por terem passado por repastos sucessivos.

Ainda em relação à infecção, A. darlingi pode ser mencionada também como vetor nessas áreas pela extensão de ocorrência nesses locais de autoctonia onde as amostras foram obtidas e pelo fato de que, freqüentemente, é a única espécie em contato com o homem. Contudo, não se pode excluir que outras espécies também sejam transmissoras em Ariquemes. ARRUDA et al.2 relatam que no Pará, além de $\mathbf{A}$. darlingi, outras espécies foram encontradas infectadas - A. nuñez-tovari, A. triannulatus, A. albitarsis e A. oswaldoi, por meio de testes de radioimunoensaio e testes imunoenzimáticos, com anticorpos monoclonais (IRMA e ELISA). Estudos recentes realizados na linha $C 90$ do Pólo de Assentamento "Burareiro", por meio de testes imunoenzimáticos (ELISA), foram registradas infecção por Plasmodium vivax para $\mathbf{A}$. strodei, A. nuñez-tovari, A. triannulatus, $A$. galvaoi e A. peryassui. A infecção pelas duas espécies de Plasmodium foi registrada apenas para A. darlingi (TADEI et al. ${ }^{37}$, comunicação preliminar). Os dados foram discutidos considerando os casos de malária na localidade, a densidade da população de anofelinos e a incidência das espécies picando o homem e os animais. Tais resultados revelaram alto índice de infecção para A. galvaoi e os estudos de densidade mostraram um contato inaior da espécie com o homem, para o período de maior infecção. Foi verificado, também, que há uma fração residual da população de $\mathbf{A}$. darlingi em contato com o homem, nos períodos de densidade baixa, e foi aventada a hipótese de que esta fração está relacionada com a manutenção da transmissão da malária. Com base nestes resultados, é possível que outras espécies estejam envolvidas na transmissão em Ariquemes.

\section{RELAÇÃO DE ESPÉCIES E RESPECTIVOS NÚMEROS UTILIZADOS NAS TABELAS 5 A 9}

1-Anopheles darlingi

2 - Anopheles Iriannulatus

3 -- Anopheles galvaoi

4 - Anopheles peryassui

\author{
5 - Anopheles rangeli \\ 6 - Anopheles argyritarsis \\ 7 - Anopheles mediopunctatus \\ 8 - Anopheles evansae \\ 9 - Anopheles benarrochi \\ 10 - Anopheles nuñez-tovari \\ 11 - Anopheles oswaldoi \\ 12 - Anopheles albitarsis \\ 13 - Anopheles braziliensis \\ 14 - Anopheles mattogrossensis \\ 15 - Anopheles strodei
}

\section{SUMMARY}

Biology of Amazonian anophelines. XII. Species of Anopheles, transmission dynamics and control of malaria in the urban area of Ariquemes (Rondonia, Brazil)

Data on the prevalence and distribution of species of Anopheles in Ariquemes (State of Rondonia) show. that the diversity is greater at the periphery of the town and that Anopheles darlingi is recorded at nearly all of the sampling points. The entomological survey revealed different levels of penetration by $\mathbf{A}$. darlingi into the urban area: Sectors 1 and 3 are free of malaria transmission, Sectors 2 and 4 show risks at the periphery, and the Industrial Sector, Sector of Special Areas, BNH housing estate, Sector 5 and the Old Town are areas of high risk for malaria. These areas had the highest indices of mosquitoes per man-hour, with variations of this index during the sampling period and depending on locality. Measures of population density showed seasonal variation, with the lowest indices during the rainy season. Malaria transmission is discussed in relation to 1) the physical structure of the town at the time it was jounded; 2) the streams that border the urban area and their relation to the life cycle of the anophelines; 3 ) biting activity of the species colected in natural environments and areas altered by man; and 4) the importance of environmental management for malaria control by reducing the vector population density. To reduce the penetration of urban areas by mosquitoes from the surrounding countryside, a protective belt around the town is proposed. This belt should be of sparse forest and include alternative hosts 10 encourage the zoophilic tendencies of the anophelines. Infection rates 
TADEI, W.P.; SANTOS, J.M.M. dos; COSTA. W.L. de S. \& SCARPASSA, V'. H. - Biologia de anofelinos amazônicos. XII. Ocorrência de espécies de Anopheles, dinâmica da transmissão e controle da inalária na zona urbana de Ariquemes (Rondônja). Rev. Inst. Med. trop. São Paulo, 30(3):221-251, 1988.

among anophelines in areas authocthonous for malaria incriminate $\mathbf{A}$. darlingi as a vector. The possibility of transmission by other species is discussed

\section{AGRADECIMENTOS}

Agradecemos ao Sr. Gentil Valério, Prefeito de Ariquemes, pelo apoio recebido na montagem do laboratório, junto à Secretaria Municipal da Saúde, e na formação da equipe, imprescindíveis para o desenvolvimento do Projeto.

\section{REFERÊNCIAS BIBLIOGRÁFICAS}

1. ALVERSON, D.R. \& NOBLET, R. - Response of female black flies to selected meteorological factors. En viron. EnI., 5: 662-665, 1976

2. ARRUDA, M.; CARVALHO, M.B.; NISSSENZ WEIG, R.S.; MARACIC, M.; FERREIRA, A.W. \& COCHRANE, A.H. - Potential vectors ol malaria and their different susceptibility to Plasmodium falciparum and Plasmodium vivax in northern Brazil identitied by immonoassay. Amer. J. Irop. Med. Hyg., 35: $873-881,1986$

3. BOYD, M.F. - Epidemiology of malaria: factors rela ted to the intermediate host. In: BOYD, M.F., ed. Malariology. Philadelphia, W.B. Saunders, 1949. ․ 1 , p. 551-607.

4. BRADY, J. - Circadian changes in central excitabijity - the origin of behavioural rhythms in isetse flies and other animals? J. Ent. (Ser. A), 50: 79-95, 1975

5. CHARLWOOD, J.D. \& HAYES, J. - Variaçòes geográficas no ciclo de picada do Anopheles darlingi Roo no Brasil. Acta amaz. (Manaus), 8: 601-603, 1978.

6. CHARLWOOD, J.D. \& WILKES, T.J. - Studies on the age-composition of samples of Anopheles darlingi Root (Diptera: Culicidae) in Brazil. Bull. ent. Res., 69: $337-342,1979$

7. COLUZZI, M. - Inversion polymorphism and adult emergence in Anopheles stephensi. Science, 176: 59-60. 1972

8. COLUZZI, M.; CANCRINI, G. \& DI DECO, M. Polimorfismo iromosomico e Lunghezza dell'uovo in Anopheles stephensi. Parassitologia, 14: 18-21, 1972.

9. COLUZZI, M.; DI DECO, M. \& CANCRINI, (i. Uteriori osservazioni sulla lungnezza dell'uovo in Anopheles stephensi in relazione al polimorfismo cromosomico. Parassitologia, 16: 107, 1974.

10. COLUZZ1, M.; SABATINI, A.; PFTRARCA, V. DI DECO, M.A. - Chromosomal differentiation and adaptation to human environments in the Anopheles gambie complex. Trans, roy. Soc. trop. Med. Hyg., 73: 483-497, 1979

11. COUTINHO, J.O. - Contribuicão para o conhecimento das espécies do subgênero Kertszia (1)ipteraCulicidae): sua importância na transmissão da inalária. São Paulo, 1946. (Tese de Doutoramento - Faculdade de Medicina da Universidade de Sảo Paulo).
12. COVA-GARCIA, P. -- Notas sobre los anofelinos de Venezuela y su identificación. Caracas, Editora Grafos, 1961 .

13. DALMAT, H.T. - The black flies (Diptera: Simulidae) of Guatemala and their role as vectors of onchocerciasis. Smithsonian Miscellaneous Collections, 125(1): $1-425,1955$

14. DEANE, L.M. - Observações sobre a maläia na Amazônia Brasileira. Rev. Serv. Saúde públ. (Rio de J.), 1: 3-60, 1947

15. DEANE, L.M.; CAUSEY, O.R. \& DEANE, M.P. Notas sobre a distribuição e a biologia dos anofelinos das regióes Nordestina e Amazônica do Brasil. Rev. Serv. Saúde públ. (Rio de J.), 1: 827-965, 1948.

16. DOWNS, W.G.\& PITTENDRIGH, C.S. - Bromelia Malaria in Trinidad, British West Indies. Amer. J. trop. Med., 26: 47-66, 1946.

17. ELLIOTT, R. - The influence of vector behaviour on malaria transmissor. Amer. J. Trop. Med. Hyg., 21 : 755-763, 1972

18. FARAN, M.E. \& LINTHICUM, K.J. - A handbook of the Amazonian species of Anopheles (Nyssorhynchus) (Diptera, Culicidae). Mosquito Systematics, 13: 1-81, 1981.

19. FERREIRA, E. - Distribuicão geográfica dos anofelinos no Brasil e sua relação com o estudo atual da erradicaçào da malária. Rev. bras. Malar., 16: 329-348, 1964.

20. FORATTINI, O.P. - Entomologia médica, Volume 1: Parte geral, Diptera, Anophctini. São Paulo, Faculdade de Higiene e Saúde Pública, 1962.

21. GALINDO, P.; TRAPIDO, H.; CARPENTER, S.J \& BI ANTON, F.S. - The abundance cycles of arboreal mosquitoes during six years at a sylvan yellow fever locacity in Panama. Ann. ent. Soc. America, 49: $543-547,1956$.

22. GALVÃO, A.L.A.; DAMASCENO, R.G. \& MARQUES, A.P. - Algumas observaçoses sobre a biologia dos anofelinos de importância epidemiológica de Belém, Pará. Arch. Hig. (Rio de J.), 12: 51-111, 1942.

23. JONES, M.D.R. - Inversion polymorphism and circadian flight activity in the mosquito Anopheles stephensi List. (Diptera Culicidae). Bull. ent. Res., 64: 305-311, 1974

24. JONES, M.D.R.; HILL, M. \& HOPE A.M. - The circadian flight activity of the mosquito Anopheles gambiae: phase setting by the light regime. J. exp. Biol., 47: 503-511, 1967.

25. JONES, M.D.R.; CUBBIN, C.M. \& MARSH, D. The circadian rhythm of flight activity of the mosquito Anopheles gambiae: the light response rhythm. J. exp. Hiol., 57: 337-346, 1972.

26. LACEY, L A \& CHARLWOOD, J.D - On the biting activities of some anthropophilic Amazonian Simuliidae (Diptera). Bull. ent. Res., 70: 495-509, 1980

27. LANE, J. - Neotropical Culicidae. Volume 1: Dixinae, Chaoborinac and Culinae, tribes Anophelini, Toxorhynchitini and Culicini (genus Culex only). São Paulo, University of São Paulo, 1953.

28. MAC-GREGOR, M.E. - Mosquito surveys. London, Baillière, Tindall and Cox, 1927

29. MEIRA, D.A.; PITA, H.J. \& BARRAVIERA, B. Malária no mumicípio de Humaitá, Estado do Amazonas. 1. Alguns aspectos epidemiológicos e clínicos. Rev. Inst. Med. trop. S. Paulo, 22: 124-134, 1980. 


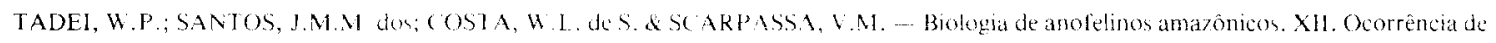

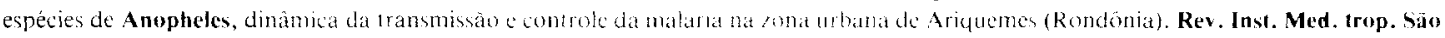
Paulo, 30(3):221-251, 1988.

30. MORAN, E.F. - Developing the Amazon. Bloomington, Indiana University Press. 1981.

31. RACHOU, R.G. - Anofelinos do Brasil: comportamento das espécies vetoras de malária. Rev. bras. Malar., 10: 145-181, 1958.

32. ROBERTS, D.R.; HOCH, A.L.; PETERSON, N.E. \& PINHEIRO, F.P. - Programa multidisciplinario de vigilancia de las enfermedades infecciosas en zonas colindantes con la carretera transamazonica en Brazil. IV. Estudio entomologico. Bol. Ofic. sanit. panamer., 91: 379-400, $198 \mathrm{I}$.

33. STANDFAST, H.A. \& BARROW, G.J. - Studies on the epidemiology of arthropod-borne virus infections at Mitchell River Mission, Cape York Peninsula, North Queensland. 1. Mosquito collections, 1963-1966. Trans. roy. Soc. trop. Med. Hyg., 62: 418-429, 1968.

34. TADEl, W.P. - Dinámica da transmissão da malária humana na zona urbana da cidade de Ariquemes (Rondônia). Ciênc. e Cult., 37: 65, 1985.

35. TADEI, W.P. - Biologia de anol linos amazônicos. $X$. Ocorrência de especies de Anopheles nas áreas de in fluência das Hidrelétricas de Tucurui (Para) e Balbina (Amazonas). Rev. bras. Engenh., 1(4): 71-78, 1986.

36. TADEl, W.P. - Biologia de anotelinos amazônicos. X1. Estudos em populaçes de Anopheles e controle da malária em Ariquemes (Rondônia). Acta amaz. (Manaus), 18 (Suplemento Polonoroeste), 1988a

37. TADEI, W.P.; CARVALHO, M.B.; SANTOS,
J.B.M.F.; FERREIRA, A.W. \& NUSSENZWEIG, R.S. - Dinâmica da transmissão da malária em Rondònia e suscetibilidade das espécies de Anopheles aos Plasmodium vivax e Plasmodium falciparum, identificada por teste imonoenzimático. In: CONGRESSO DA SOCIEDADE BRASILEIRA DE MEDICINA TROPICAL, 24., Manaus, 1988. Programa e resumos. Manaus, 1988. p. 26, res. n? 019.

38. TADEI, W.P. \& CORREIA, J.M. - Biologia de anofelinos amazônicos. IV - Observaçoes sobre a atividade de picar de Anopheles nuñez-tovari Gabaldón (Diplera, Culicidae). Acta amaz. (Manaus), 12: 71-74, 1982.

39. TADEL, W.P.; MASCARENHAS, B.M. \& PODESTÁ, M.C. - Biologia de anofelinos amazônicos. VIII. Conhecimentos sobre a distribuiçào de espécies de Anopheles na regiáo de Tucurui - Marabá (Pará). Acta amaz. (Manaus), 13: 103-140, 1983.

40. TADEI, W.P. \& SANTOS, J.M.M. - Biologia de anofelinos amazónicos. VII. Estudo da variação de freqieências das inversòes cromossômicas de Anopheles darlingi Root (Diptera, Culcidae). Acta amaz. (Manaus), 12: 759-785, 1982

41. VAN THIEL, P.H. -- Malaria problems arising from the construction of a reservoir in the interior of Surinam. Trop. geogr. Med., 14: 259-278, 1962.

42. WOLDA, H \& GALINDO, P. - Population fluctuations of mosquitoes in the non-seasonal Tropics. Ecol. Ent. 6: 99-106, 1981 